\title{
RESEÑAS DE CUENTOS APARECIDAS EN LOS DIARIOS ABC (ABC CULTURAL) Y EL PAÍS (BABELIA) 1996-1999
}

\author{
Francisco Linares Valcárcel \\ Dolores Romero López
}

Grupo de Investigación del ISLTYNT-UNED

\section{CUENTOS EN ESPAÑOL}

1. España

a) Obras

Acín, Ramón (1999). Los que están al filo. Barcelona: DVD Ediciones. Reseña: J[avier] G[OÑI] (1999). «Ocho equilibrios en el alambre». El País (Babelia 421), 11-12, 6.

Alarcón, Pedro Antonio de (1998). La mujer alta. La comendadora. Barcelona: Plaza y Janés. Reseña: C[arlos] P[UJOL] (1998). «La mujer alta/La comendadora». ABC (ABC Cultural 354), 10-9, 14.

AlCÁNTARA, Ricardo y CAPDEVILA, Roser (1997). Simbarba y las gaviotas. Barcelona: La Galera. Reseña: P. P. (1997). «Un pirata que no sabe nadar». El País (Babelia 285), 19-4, 14. 
Álvarez De Miranda, Sarah (1996). El vecino de Eaton Square. Oviedo: Trabe. Reseña: CASTRO, Pilar (1996). «El vecino de Eaton Square». ABC (ABC Cultural 248), 2-8, 10.

Amo, Álvaro del (1998). Incandescencia. Barcelona: Anagrama. Reseña: ConTE, Rafael (1998). «De fuegos incombustibles». $A B C$ ( $A B C$ Cultural 355), 17-9, 9.

Antoñana, Pablo (1999). Extraña visita y otras historias. Pamplona: Pamiela. Reseña: GoÑI, Javier (1999). «El horror de la guerra». El País (Babelia 419), 27-11, 5.

ARAMBURU, Fernando (1997). No ser no duele. Barcelona: Tusquets. Reseñas: SENABRE, Ricardo (1997). «No ser no duele». $A B C$ (ABC Cultural 315), 14-11, 13. GoÑI, Javier (1998). «Una mirada descarnada». El País (Babelia 323), 10-1, 9.

ARGÜELLES, Fulgencio (1998). Del color de la nada. Oviedo: KRK (Ilustraciones de Eduardo Argüelles). Reseña: ORTEGA, Antonio (1999). «Espejos de ceniza». $A B C$ ( $A B C$ Cultural 377), 20-2, 10.

ARrufat, Antón (1997). De las pequeñas cosas. Valencia: Pre-Textos. Reseña: GoÑI, Javier (1997). «El apresador de instantes fugaces». El País (Babelia 295), 28-6, 11.

ATXAGA, Bernardo (1997). Historias de Obaba. Barcelona: Ediciones B. Reseña: GoÑI, Javier (1997). «Geografías imaginarias y reales». El País (Babelia 297), 12-7, 10.

AtXaga, Bernardo; Fajardo, José Manuel; Gamboa, Santiago; Sarabia, Antonio y SEPÚlvedA, Luis (1999). Cuentos apátridas. Barcelona. Ediciones B. Reseñas: MARÍN, Juan (1999). «Relatos contra las fronteras». El País (Babelia 396), 19-6, 11. RodríGuEZ-FisCHER, Ana (1999). «Sin fronteras». $A B C$ (ABC Cultural 399), 18-9, 18.

Ayerra, Ramón (1996). Plaza Weyler. Madrid: Huerga \& Fierro. Reseña: J[avier] G[OÑI] (1996). «Ironía y humor en cuento de la mili». El País (Babelia 252), 24-8, 12.

AzoRín [José Martínez Ruiz] (1998). Teatro, cuentos, memorias, epistolario. Madrid: Espasa-Calpe (Volumen III, edición de M. Á. Lozano Marco). Reseña: García-PosADA, Miguel (1998). «La edición de un clásico». El País (Babelia 366), 14-11, 7.

BARGA, Corpus [Seud. de Andrés García de la Barga y Gómez] (1997). Contando sus pasos. Valencia: Pre-Textos (Edición de Isabel del Álamo). Reseña: Pujol, Carlos (1998). «Contando sus pasos». ABC (ABC Cultural 328), 13-2, 15.

Baroja, Pío (1997). Cuentos de amor y muerte. Madrid: Ediciones Clan (Introducción de Jesús Gálvez Yagüe e ilustraciones de Marina Arespacochaga). Reseñas: Trapiello, Andrés (1997). «Pío Baroja y la fiera humana». El País (Babelia 297), 12-7, 11. ConTE, R[afael] 
(1997). "Cuentos de amor y de muerte». ABC (ABC Cultural 306), $12-$ $9,20$.

BARREIRO, Javier (1996). El desastre de nuestras fiestas. Zaragoza: Xordica. Reseñas: I. de la F. (1997). «Relatos trepidantes y corrosivos». El País (Babelia 273), 18-1, 9. SENABRE, Ricardo (1997). «El desastre de nuestras fiestas». ABC (ABC Cultural 260), 25-10, 10.

BENET, Juan (1998). Cuentos completos. Madrid: Alfaguara. Reseñas: DE LOPE, Manuel (1998). «Benet y los caminos forestales». El País (Babelia 329), 28-2, 15. R. B. (1997). «Cuentos completos inaugurará la Biblioteca Benet». El País (Babelia 304), 30-8, 9. CoNTE, Rafael (1998). «Volverás a Juan Benet». $A B C$ ( $A B C$ Cultural 365$), 26-11,8$.

- (1998). Trece fábulas y media y fábula decimocuarta. Madrid: Alfaguara. Reseñas: CONTE, Rafael (1998). «Volverás a Juan Benet». $A B C$ ( $A B C$ Cultural 365), 26-11, 8. DE LOPE, Manuel (1998). «Benet y los caminos forestales». El País (Babelia 329), 28-2, 15.

BENÍTEZ ARIZA, José Manuel (1998). La sonrisa del diablo. Sevilla: Renacimiento. Reseña: J[avier] G[OÑI] (1998). «Una cierta melancolía». El País (Babelia 363), 24-10, 6.

- (1999). El hombre del velador. Cádiz: Ayuntamiento de Cádiz. Reseña: J[avier] G[oÑI] (1999). «José Manuel Benítez Ariza: el sastrecillo valiente». El País (Babelia 414), 23-10, 7.

BeníteZ Reyes, Felipe (1997). Maneras de perder. Barcelona: Tusquets. Reseñas: SENABRE, Ricardo (1997). "Maneras de perder». ABC (ABC Cultural 293), 13-6, 12. GARCía PosADA, Miguel (1997). «Las carambolas de la vida». El País (Babelia 294), 21-6, 13.

BoLAÑo, Roberto (1997). Llamadas telefónicas. Barcelona: Anagrama. Reseña: EchEVARría, Ignacio (1997). «Relatos de supervivientes». $E l$ País (Babelia 318), 6-12, 9.

BonLla, Juan (1996). El arte del yo-yo. Valencia: Pre-Textos. Reseña: CAsTRO, Pilar (1997). «El arte del yo-yo». ABC (ABC Cultural 272), 17-1, 10. CALCEDo, Gonzalo (1997). Esperando al enemigo. Barcelona: Tusquets. Reseña: Ayala-DIP, J. Ernesto (1997). «Destinos poco envidiables». El País (Babelia 281), 15-3, 10.

- (1999). La madurez de las nubes. Barcelona: Tusquets. Reseñas: AyAlADIP, J. Ernesto (1999). «Fragmentos de vida». El País (Babelia 381), $27-$ 2, 6. RodRíGUEZ-FISCHER, Ana (1999). «Atardeceres rotos». $A B C$ ( $A B C$ Cultural 377), 20-2, 12.

Caro Baroja, Julio (1996). Las veladas de Santa Eufrosina. Madrid: Caro Raggio. Reseña: SENABRE, Ricardo (1996).«Las veladas de Santa Eufrosina». $A B C$ (ABC Cultural 220), 19-1, 7.

CASARIEGo, Nicolás (1998). La noche de las doscientas estrellas. Madrid:

Lengua de Trapo. Reseña: CASTRO, Antón (1998). «Las armas secretas 
del boxeador». $A B C$ (ABC Cultural 363), 12-11, 10. AyALA-DiP, J. Ernesto (1998). «Un mundo de turbiedades». El País (Babelia 367), 21$11,10$.

CASTÁn, Carlos (1997). Frío de vivir. Zaragoza: Zócalo Editorial. Reseña:

De La PeÑa, Luis (1997). «Un frío paisaje interior». El País (Babelia 297), 12-7, 10.

- (1997). Frío de vivir. Barcelona: Emecé. Reseña: SANTos, Care (1998). «Frío de vivir». ABC (ABC Cultural 327), 6-2, 14.

CASTRO, Antón (1998). Los seres imposibles. Barcelona: Destino. Reseñas: CONTE, Rafael (1998). «Meigas en el Maestrazgo». $A B C$ ( $A B C$ Cultural 361), 29-10, 10. MARín, Juan (1998). «Donde nada es mentira». El País (Babelia 366), 14-11, 6.

Cela Trulock, Jorge (1999). Sale el sol y ocho cuentos más. Madrid: Calambur. Reseña: J[avier] G[OÑI] (1999). «Cuentos de un miniador de la prosa». El País (Babelia 408), 11-9, 8.

CERDA, Martha (1999). La señora Rodríguez y otros mundos. Barcelona:

Ediciones B. Reseña: DE LA PEÑA, Luis (1999). «El mundo dentro de un bolso». El País (Babelia 415), 30-10, 10

CHIRBES, Rafael (1997). Mediterráneos. Madrid: Debate. Reseña: MARCo, Joaquín (1997). «Mediterráneos». ABC (ABC Cultural 313), 31-10, 10. CID, Gabriel (1997). Hágase Vd. inmortal. Madrid: Anaya \& Mario Muchnik. Reseñas: S. F. (1997). «Corpúsculos y mundo selvático». El País (Babelia 316), 22-11, 10. CASTRO, Pilar (1998). «Hágase usted inmortal». $A B C$ (ABC Cultural 323), 9-1, 14.

CONGET, José María (1998). Hasta el fin de los cuentos. Valencia: Pre-Textos. Reseña: GoÑI, Javier (1998). «Érase que se era». El País (Babelia 346), 27-6, 12.

De LA RosA, Julio Manuel (1997). La columna y otros relatos. Sevilla: Alfar. Reseña: García-Posada, Miguel (1997). «Mitos y realidades». El País (Babelia 303), 23-8, 9.

De Prada SAMPER, José Manuel (1998). Las mil caras del diablo. Barcelona: Juventud (Ilustraciones de Luis Filella). Reseña: R. B. (1998). «Relatos sobre el diablo de 30 culturas diferentes». El País (Babelia 360), 3-10, 10.

De VILlENA, Luis Antonio (1999). El mal mundo. Barcelona: Tusquets (XXI Premio «La Sonrisa Vertical»). Reseñas: VILLORA, Pedro Manuel (1999). «Cuando son soldados y están solos». $A B C$ ( $A B C$ Cultural 382), 27-3, 10. GoÑI, Javier (1999). «Pasión y melancolía». El País (Babelia 389), 15,7 .

- (1999). La fascinante moda de la vida. Barcelona: Planeta. Reseña: VILlORA, Pedro Manuel (1999). «La fascinante moda de la vida». ABC (ABC Cultural 396), 10-7, 24. 
Del Amo, Álvaro (1998). Incandescencia. Barcelona: Anagrama. Reseña: García-Posada, Miguel (1998). «Las tensiones del mundo». El País (Babelia 359), 26-9, 6.

Del Río, Isabel (1995). La duda. Barcelona: Tusquets (Finalista del I Premio Nuevos Narradores). Reseña: BASANTA, Ángel (1996). «La duda». ABC (ABC Cultural 218), 5-1, 9.

ESQUIVEL, Laura (1998). Íntimas suculencias. Tratado filosófico de cocina. Madrid: Ollero \& Ramos. Reseña: J[avier] G[OÑ] (1998). «Las íntimas suculencias culinarias de Laura Esquivel». El País (Babelia 357), 26-9, 3. ESTEBAN, Alicia; AGUIRRE, Mercedes (1998). Cuentos de la mitología griega III. En el mar. Madrid: Ediciones de La Torre (Ilustraciones de Siro López). Reseña: MENDIOLA, Jorge (1999). «Cuentos de la mitología griega. En el mar». ABC (ABC Cultural 375), 4-2, 24.

ETXEBARRIA, Lucía (1999). Nosotras que no somos como las demás. Barcelona: Destino. Reseña: J. C. (1999). «Modelos de disidencia sexual». $E l$ País (Babelia 399), 10-7, 10.

F. M. (1997). Cuentos de $X, Y$ y Z Madrid: Lengua de Trapo. Reseñas: SANTos, Care (1997). "Cuentos de X, Y y Z». ABC (ABC Cultural 321), 2612, 12. Ayala-DIP, J. Ernesto (1998). «Escribir bajo iniciales». El País (Babelia 323), 10-1, 11.

FERNÁNDEZ CUBAS, Cristina (1998). Los altillos de Brumal / En el hemisferio Sur. Barcelona: Plaza y Janés (Colección «Relatos» dirigida por Ana María Moix). Reseña: Pujol, Carlos (1998). «Trayectos cortos». $A B C$ (ABC Cultural 356), 24-9, 14.

FERNÁNDEZ-SANTOS, Francisco (1999). La casa del ángel. Madrid: Huerga \& Fierro. Reseña: DE LA PEÑA, L[uis] (1999). «Catorce títulos sobre la condición humana». El País (Babelia 401), 24-7, 7.

FRABETTI, Carlo (1999). La ciudad rosa y roja. Madrid: Lengua de Trapo.

Reseña: AyALA-DiP, J. Ernesto (1999). «Influencias manifiestas». El País (Babelia 416), 6-11, 8.

FraIle, Medardo (1998). Contrasombras. Valencia: Pre-Textos. Reseñas: BASANTA, Ángel (1998). «Contrasombras». ABC (ABC Cultural 348), 37, 12. García-Posada, Miguel (1998). «Las luces de los cuentos». El País (Babelia 353), 22-8, 10.

GalA, Antonio (1998). El corazón tardío. Madrid: Espasa-Calpe / Planeta.

Reseñas: De la PeÑa, Luis (1998). «Cuentos de Antonio Gala». El País (Babelia 336), 18-4, 12. BASANTA, Ángel (1998). «El corazón tardío». $A B C$ (ABC Cultural 340), 8-5, 14.

García De Diego, Vicente (1999). Leyendas de España. Barcelona: Círculo de Lectores (Prólogo de Carlos García Gual). Reseña: RuIz CaSANova, José Francisco (1999). «Cuenta la leyenda...». $A B C$ ( $A B C$ Cultural 407), 13-11-99: 22. 
García HoRTElano, Juan (1997). Cuentos completos y crónicas compartidas. Madrid: Alfaguara (Prólogo de Juan Cruz). Reseñas: GARcíAPosada, Miguel (1997). «Memoria histórica de García Hortelano». El País (Babelia 288), 10-5, 13. ConTE, Rafael. «Cuentos completos y crónicas compartidas». ABC (ABC Cultural 292), 6-6, 7.

García Morales, Adelaida (1996). Mujeres solas. Barcelona: Plaza \& Janés. Reseña: DE LA PEÑA, Luis (1997). «Consumadas soledades». El País (Babelia 272), 11-1, 12.

García Pavón, Francisco (1996). Obras completas. Ciudad Real: Ediciones Soubriet (4 volúmenes). Reseñas: CONTE, Rafael (1997). «Obras completas». ABC (ABC Cultural 274), 31-1, 11. DE LA PEÑA, Luis (1997). «Toda la obra de García Pavón». El País (Babelia 280), 1-3, 14.

GarCíA-JAMBrina, Luis (1995). Oposiciones a la Morgue y otros ajustes de cuentas. Madrid: Valdemar. Reseña: M[iguel] G[ARCía]-P[OSADA] (1996). «Lo duro, lo sucio». El País (Babelia 225), 10-2, 10.

GimÉnez Corbatón, José (1997). Tampoco esta vez dirán nada. Madrid: Anaya Mario Muchnik. Reseña: SANTOS, C[are] (1998). «Tampoco esta vez dirán nada». $A B C$ ( $A B C$ Cultural 347), 26-6, 13.

Gómez OJeA, Carmen (1995). Barcelona: Destino. L[uis] DE LA P[EÑA] (1996). «Carmen Gómez Ojea: una mirada en la luna». El País (Babelia 221), 13-1, 11.

GoNZÁlEZ LeÓN, Adriano (1998). Todos los cuentos más uno. Madrid: Alfaguara. Reseña: Pozuelo Yvancos, José María (1999). «Fortuna de la brevedad». $A B C$ (ABC Cultural 375), 4-2, 13.

GonZÁLEZ, Javier (1998). Frigoríficos en Alaska. Madrid: Debate. Reseñas: CASTRO, Antón (1998). «Un temblor en las entrañas». $A B C$ ( $A B C$ Cultural 358), 8-10, 11. AYALA-DIP, J. Ernesto (1998). «La vida, en pocas palabras». El País (Babelia 361), 10-10, 7.

Grandes, Almudena (1996). Modelos de mujer. Barcelona: Tusquets (Premio NH de relatos). Reseñas: R. B. (1997). «Almudena Grandes gana el primer premio NH de relatos». El País (Babelia 274), 25-1, 11. GoÑ, Javier (1996). «La pasión escoge a sus víctimas». El País (Babelia 232), 30-3, 8. CASTRO, Pilar (1996). «Modelos de mujer». ABC (ABC Cultural 230), 29-3, 10.

Gullón, Germán (1997). Adiós, Helena de Troya. Barcelona: Destino. Reseña: DE LA PEÑA, Luis (1998). «El espectáculo irónico de la realidad». El País (Babelia 326), 21-1, 12.

HATERo, Josán (1996). Biografías de la huida. Madrid: Debate. Reseña: R. B. (1996). «Sexo, drogas, coches, amistad y discotecas». El País (Babelia 238), 18-5, 9.

HERNÁNDEZ BECERRA, Gustavo (1997). Cuentos sobre el fracaso de lo cotidiano. Barcelona: Ediciones del Bronce. Reseña: L[uis] de la P[eña] 
(1997). «Cuentos sobre el fracaso de lo cotidiano». El País (Babelia 313), 1-11, 11.

HerranZ, Jesús (1998). Ojáncanos. Madrid: Anaya (Varios ilustradores). Reseña: R. B. (1999). «Los terribles Ojáncanos siguen vivos». El País (Babelia 375), 16-1, 7.

HuerTas, Begoña (1996). A tragos. Madrid: Debate. Reseña: SANTos, Care (1997). «A tragos». ABC (ABC Cultural 270), 3-1, 10.

IBARRA, Julia (1997). Todos adorábamos el negro. Barcelona: Editorial El Clavell (Prólogo de Emilio Alarcos). Reseña: P[ilar] C[astro] (1998). «Todos adorábamos el negro». ABC (ABC Cultural 324), 16-1, 14.

IRISARRI, Ángeles (1995). Siete cuentos históricos. Zaragoza: Zócalo. Reseña: CASTRO, Pilar (1996). "Siete cuentos históricos». ABC ( $A B C$ Cultural 220), 19-1, 10.

- (1997). Diez relatos de Goya y su tiempo. Zaragoza: Diputación General de Aragón (Premio Baltasar Gracián de Narrativa). Reseña: SANTos, Care (1997). «Diez relatos de Goya y su tiempo». ABC (ABC Cultural 318), 5-12, 13.

IRISARRI, Ángeles y LASALA, Magdalena (1998). Moras y cristianas. Barcelona: Emecé. Reseñas: OBIOL, María José (1998). «Cinco sentidos de las raíces españolas». El País (Babelia 344), 13-6, 11. CAStro, Pilar (1998). "Moras y cristianas». ABC (ABC Cultural 347), 26-6, 14.

JiMÉNEZ LoZANO, José (1996). Un dedo en los labios. Madrid: Espasa Calpe. Reseñas: MARCo, Joaquín (1996). "Un dedo en los labios». ABC (ABC Cultural 224), 16-2, 19. PEREDA, Rosa (1996). «La terrible condición». El País (Babelia 229), 9-3, 12.

JiMÉNEZ, Juan Ramón (1999). Cuentos de antolojia. Madrid: Clan. Reseña: LONGARES, Manuel (1999). «La narrativa de Juan Ramón Jiménez». El Pais (Babelia 420), 4-12, 7.

LATORRE, José María (1999). Relatos desde la muerte. Alicante: Epígono. Reseña: SATORRAS, Lluis (1999). «Narraciones de terror». El País (Babelia 387), 17-4, 6.

LeANTE, Luis (1996). El criador de canarios. Madrid: Ópera Prima. Reseña: Santos, Care (1996). "El criador de canarios». ABC (ABC Cultural 245), 12-7, 10.

LloP, José Carlos (1999). La novela del siglo. Barcelona: Muchnik. Reseñas: Ayala-Dip, J. Ernesto (1999). "Voces salidas de la niebla». El País (Babelia 398), 3-7, 7. ROMEO, Félix (1999). "La novela del fin de siglo» $A B C$ (ABC Cultural 390), 29-5, 24.

LONGARES, Manuel (1999). Extravíos. Madrid: Alfaguara. Reseñas: CASTEJóN, Encarna (1999). «Malicia del alambique». $A B C$ ( $A B C$ Cultural 376), 13-2, 18. GoÑI, Javier (1999). «Los desvarío de la realidad». El País (Babelia 380), 20-2, 6. 
LÓPEZ SARASÚA, Concha (1997). La daga turca y otros relatos mediterráneos. Alicante: Cálamo. Reseña: M. B. (1997). «Relatos entre lo fantástico y lo realista». El País (Babelia 282), 22, 3, 12.

LUEIRO, Manuel (1998). Hundezelle y otras vidas maltratadas. Barcelona: Ronsel. Reseña: DE LA PEÑa, Luis (1999). «Edición póstuma de los cuentos de Lueiro». El País (Babelia 380), 20-2, 6.

MACHADO, Manuel (1999). Cuentos completos. Madrid: Clan Editorial. Reseña: M. L. (1999). «La prosa narrativa de Manuel Machado». El País (Babelia 403), 7-8, 9.

MAGRINYÁ, Luis (1995). Belinda y el monstruo. Madrid: Debate. Reseña: BASANTA, Ángel (1996). «Belinda y el monstruo». ABC (ABC Cultural 225), 23-2, 10.

MALVIDO, Gonzalo T. (1996). Doce cuentos ejemplares. Madrid: Alfaguara. Reseña: GoÑı, Javier (1996). «De ambientes acanallados». El País (Babelia 263), 9-11, 10.

MaÑAS, Pilar (1996). El salario de la seda. Granada: Diputación Provincial. Reseña: SANTOS, Care (1996). «El salario de la seda». ABC (ABC Cultural 254), 13-9, 9.

MARÍAS, Javier (1998). Mala índole. Barcelona: Plaza y Janés (Colección «Relatos» dirigida por Ana María Moix). Reseña: Pujol, Carlos (1998). «Trayectos cortos». $A B C$ ( $A B C$ Cultural 356), 24-9, 14.

- (1996). Cuando fui mortal. Madrid: Alfaguara. Reseña: CASTRo, Pilar (1996). «Cuando fui mortal». ABC (ABC Cultural 225), 23-2, 11.

- (1998). Cuando fui mortal. Madrid: Alfaguara. Reseña: J[avier] G[oÑI] (1998). «Relatos de bolsillo de Javier Marías». El País (Babelia 356), 5$9,8$.

MARTÍN, Andreu (1996). Fantasmas cotidianos. Barcelona: Planeta. Reseña: CASTRO, Pilar (1997). «Fantasmas cotidianos». ABC (ABC Cultural 270), 3-1, 9.

Martínez Dalmases, Francisco (1999). El legado. Crónica de las tierras de exilio. Barcelona: Kairós. Reseña: DE LA PEÑA, Luis (1999). «En el reino de lo maravilloso». El País (Babelia 400), 7-7, 8.

MARTínez De PISÓN, Ignacio (1996). El tesoro de los hermanos Bravo. Barcelona: Alba Editorial. Reseña: SANTos, Care (1996). «El tesoro de los hermanos Bravo». ABC (ABC Cultural 246), 19-7, 10.

- (1998). Foto de familia. Barcelona: Anagrama. Reseñas: SENABRE, Ricardo (1998). «Foto de familia». ABC (ABC Cultural 326), 30-1, 15. PuIG, Valenti (1998). «Álbum de enemigos interiores». El País (Babelia 329), 28-2, 15.

MASOLIVER RóDENAS, Juan Antonio (1996). La sombra del triángulo. Barcelona: Anagrama. Reseña: EcheVARRíA, Ignacio (1996). «El paso adelante». El País (Babelia 229), 9-3, 12. 
Mateo Díez, Luis (1997). Días del desván. León: Edilesa. Reseña: SenABRE, Ricardo (1997). «Días del desván». $A B C$ (ABC Cultural 313), 3110,11 .

MatuTE, Ana María (1997). Casa de juegos prohibidos. Madrid: EspasaCalpe (Edición de Pedro Manuel Villora). Reseña: CASTRO, Pilar (1997). "Casa de juegos prohibidos». ABC (ABC Cultural 297), 1-7, 10.

- (1998). Los de la tienda /El maestro /Toda la brutalidad del mundo. Barcelona: Plaza y Janés (Colección «Relatos» dirigida por Ana María Moix). Reseña: Pujol, Carlos (1998). «Trayectos cortos». $A B C$ ( $A B C$ Cultural 356), 24-9, 14.

MAYORAL, Marina (1998). Recuerda, cuerpo. Madrid: Alfaguara. Reseñas: FONTANA, Antonio (1998). «Celebración del cuerpo». ABC (ABC Cultural 362), 5-11, 14. De la PEÑA, Luis (1998). «Cuentos sobre el deseo». El País (Babelia 365), 7-11, 6.

MEDIO, Dolores (1996). Cinco cartas de Alemania. Madrid: Huerga \& Fierro. Reseña: L[uis] D[E] L[A] P[EÑA] (1996). «El rigor de lo testimonial en Dolores Medio». El País (Babelia, 266) 30-11, 14.

MenÉndez-Ponte, María (1997). Un plato de blandiblú. Madrid: SM. Reseña: V. F. (1997). «Cómo estimular el gusto por las espinacas». $E l$ País (Babelia 306), 13-9, 8.

MerINo, José María (1997). Cincuenta cuentos y una fábula. Madrid: Alfaguara. Reseña: GoÑI, Javier (1998). «El buscador de prodigios». El País (Babelia 333). 21-3, 10.

- (1997). Cuentos. Madrid: Alianza. Reseña: GoÑı, Javier (1997). «Lecturas de verano». El País (Babelia 301), 9-8, 11.

- (1999). Cuatro nocturnos. Madrid: Alfaguara. Reseña: Romeo, Félix (1999). «Fidelidad al doble». $A B C$ (ABC Cultural 383), 10-4, 24.

MonCADA, Jesús (1996). Historias de la mano izquierda. Zaragoza: Xórdica. Reseña: CASTRo, Pilar (1996). "Historias de la mano izquierda». $A B C$ (ABC Cultural 242), 21-6, 10.

- (1997). El ojo izquierdo de Tomás D'Atura. Madrid: Alianza. Reseña: GoÑI, Javier (1997). «Lecturas de verano». El País (Babelia 301), 9$8,11$.

MONTERo, Rosa (1998). Amantes y enemigos (Cuentos de parejas). Madrid: Alfaguara. Reseñas: FUERTES, Sol (1998). «Rosa Montero o el amor es una mentira». El País (Babelia 336), 18-4, 12. CASTRO, Pilar (1998). $A B C$ (ABC Cultural 338), 24-4, 14.

Monteserín, Pepe (1999). El viajero que huye. Madrid: Lengua de Trapo. Reseña: J[avier] G[OÑI] (1999). «Pepe Monteserín no deja indiferente». El País (Babelia 399), 10-7, 10.

Monzó, Quim (1997). Guadalajara. Barcelona: Anagrama. Reseña: CASTRo, Pilar (1997). «Guadalajara». (ABC Cultural 300), 1-8, 10. 
Morán, Fernando (1997). El día en que.... Madrid: Alfaguara. Reseñas: GoÑI, Javier (1997). «Escenas de la vida diplomática». El País (Babelia 320), 20-12, 9. ConTE, Rafael (1997). «El día en que...». ABC (ABC Cultural 321), 26-12, 12.

MuRADO, Miguel Anxo (1997). Ruido. Relatos de guerra. Barcelona: Montesinos. Reseña: FERNÁNDEZ CUESTA, M. ${ }^{\mathrm{a}}$ V. (1998). «Ruido. Relatos de guerra». $A B C$ (ABC Cultural 333), 20-3, 30.

MuRCIANO, Carlos (1996). Nunca olvides las letras de mi nombre. Zaragoza: Edelvives. Reseña: SENABRE, Ricardo (1996). «Nunca olvides las letras de mi nombre». ABC (ABC Cultural 232), 12-4, 10.

Navales, Ana María (1999). Cuentos de Bloomsbury. Madrid: Calambur. Reseña: J[avier] G[OÑ] (1999). «Relatos en torno al grupo de Bloomsbury». El País (Babelia 416), 6-11, 10.

NAVARRO, Hipólito G. (1996). El aburrimiento, Lester. Madrid: Anaya \& Muchnick. Reseña: DE LA PEÑA, Luis (1996). «Una pequeña y divertida locura». El País (Babelia 268), 14-12, 8.

OrTEGa SPOTtorno, José y BALlesteros, Mercedes (1995). Los amores de cinco minutos. Madrid: El País-Aguilar. Reseña: M[iguel] G[ARCíA]P[OSADA] (1996). «Relatos de una pasión efímera». El País (Babelia 221), 13-1, 14.

OrTZ, Lourdes (1998). Fátima de los naufragios. Barcelona: Planeta. Reseñas: De LA PEÑA, Luis (1998). «Sobre las almas heridas». El País (Babelia 347), 4-7, 12. CASTRO, Pilar (1998). «Fátima de los naufragios». $A B C$ (ABC Cultural 350), 17-7, 13.

Palma, Félix J. (1998). El vigilante de la salamandra. Valencia: Pre-Textos. Reseña: GoÑI, Javier (1999). «El cazador de crepúsculos». El País (Babelia 374), 9-1, 7.

- (1999). Métodos de supervivencia. Cádiz: Fundación Municipal de Cultura del Ayuntamiento de Cádiz. Reseñas: J[avier] G[OÑI] (1999). «Helados de desconsuelo y soledad». El País (Babelia 409), 18-9, 12. FonTANA, Antonio (1999). «Segunda parte». $A B C$ ( $A B C$ Cultural 405), 30-10-96: 22.

Pardo BazÁn, Emilia (1996). Cuentos de Navidad y Reyes. Madrid: Clan. Reseña: J[avier] G[OÑI] (1997). «Nueva selección de cuentos de Pardo Bazán». El País (Babelia 276), 8-2, 10.

PASCUAL, Arturo (1996). El siglo estéril. Barcelona: Montesinos. Reseñas: X.

M. (1996). «Unos reveladores primeros relatos». El País (Babelia 232), 30-3, 8. SANTOS, Care (1996). «El siglo estéril». ABC (ABC Cultural 234), 26-4-96: 10.

PEÑA, Pedro J. de la (1996). La rosa de los vientos. Barcelona: Editorial Juventud. Reseña: BASANTA, Ángel (1996). «La rosa de los vientos». $A B C$ (ABC Cultural 255), 20-9, 10. 
Pereira, Antonio (1999). Me gusta contar. Madrid: Mario Muchnik. Reseña: GonZÁlez IGLESIAS, J. A. (1999). «Cómo contar un cuento». $A B C$ ( $A B C$ Cultural 396), 10-7, 12.

- (1999). Cuentos del Medio Siglo. Madrid: Espasa. Reseña: GonZÁleZ IgLesias, Juan Antonio (1999). «País de los Losadas y Cuentos del Medio Siglo». ABC (ABC Cultural 410), 4-12-99: 15.

Pereira, Juan Manuel (1996). El baúl de Pessoa. Barcelona: Montesinos. Reseña: SANTOS, Care. (1996). «El baúl de Pessoa». ABC (ABC Cultural 229), 22-3, 10.

PÉrez Galdós, Benito (1996). Cuentos fantásticos. Madrid: Cátedra (Edición de Alan E. Smith). Reseña: SENABRE, Ricardo (1996). ABC (ABC Cultural 237), 17-5, 19

Pérez Henares, Antonio (1998). El río de la lamia. Sevilla: Algaida. Reseña: De la PeÑA, Luis (1998). «Crónica de un territorio». El País (Babelia 352), 8-8, 11.

Pertierra, Tino (1995). Los seres heridos. Oviedo: Ediciones Nobel (Prólogo de Juan Cueto Alas). Reseña: SANTos, Care (1996). «Los seres heridos». $A B C$ ( $A B C$ Cultural 222), 2-2, 10.

Perucho, Juan (1996). Fabulaciones. Madrid: Alianza (Edición de Carlos Pujol). Reseña: CoNTE, Rafael (1996). «Fabulaciones». ABC (ABC Cultural 245), 12-7, 7.

Pombo, Álvaro (1997). Cuentos reciclados. Barcelona: Anagrama. Reseña: SENABRE, Ricardo (1997). "Cuentos reciclados». ABC (ABC Cultural 311), 17-10, 11.

PuÉRTOLAS, Soledad (1996). El recorrido de los animales. Valencia: Pre-Textos. Reseñas: J[avier] G[OÑ] (1966). «Los cuentos maternales de Soledad Puértolas» El País (Babelia, 234), 20-4, 15. M[aría] J[osé] O[віOL] (1996). «Jugar a convertirse en el animal preferido». El País (Babelia 239), 15-5, 13.

- (1998). Gente que vino a mi boda. Barcelona: Anagrama. Reseña: SENABRE, Ricardo (1998). «Gente que vino a mi boda». $A B C$ ( $A B C$ Cultural 342), 22-5, 14.

QUIÑONES, Fernando (1997). El coro de dos voces. Madrid: Anaya \& Mario Muchnik. Reseña: PEREDA, Rosa (1997). «No es bueno ser simpático». El País (Babelia 287), 3-5, 12.

- (1998). La gran temporada. Madrid: Alianza. Reseña: J[avier] G[oÑI] (1998). «La pasión taurina de Fernando Quiñones». El País (Babelia 362), 17-10, 8.

Regás, Rosa (1996). Pobre corazón. Barcelona: Destino. Reseñas: MARCo, Joaquín (1996). "Pobre corazón». ABC (ABC Cultural 263), 15-11, 11. Garcia-Posada, Miguel (1996). «Del deseo a las derrotas». El País (Babelia 264), 16-11, 15 
- (1997). Desde el mar. Madrid: Alianza. Reseña: GoÑI, Javier (1997). «Lecturas de verano». El País (Babelia 301), 9-8, 11.

Rico Godoy, Carmen (1996). La costilla asada de Adán. Madrid: Temas de Hoy. Reseña: PEREDA, Rosa (1996). «Escuchando a las mujeres». El País (Babelia 241), 8-6, 9.

RodrígueZ, Chema (1999). El diente de la ballena. Madrid: El País-Aguilar (Prólogos de Manuel Leguineche y Javier Reverte). Reseña: RuBio, Pilar (1999). «El arte del buen viajar». El País (Babelia 398), 3-7, 9.

Rodríguez, Ildefonso (1998). Son del sueño. Madrid: Ave del Paraíso.

Reseña: AYALA-DIP, J. Ernesto (1998). «Los sueños de Ildefonso Rodríguez». El País (Babelia 356), 5-9, 8.

ROMERo, César (1998). La cerilla de Faulkner. Sevilla: Capela Biblioteca.

Reseña: Sebares, P. H. (1999). "La cerilla de Faulkner». ABC (ABC Cultural 380), 13-3, 26.

ROMERO, Norberto Luis (1997). El momento del unicornio. Oviedo: Nobel.

Reseña: GoÑI, Javier (1997). «Arqueología del detritus moral». El País (Babelia 306), 13-9, 10.

Royuela, Fernando (1997). Callejero de Judas. Madrid: Lengua de Trapo. Reseña: SANTOS, Care (1997). «Callejero de Judas». ABC (ABC Cultural 293), 13-6, 9.

SALABERT, Juana (1999). Aire nada más. Barcelona: Plaza \& Janés. Reseña: GOÑI, Javier (1999). «Despojos del naufragio». El País (Babelia, 415), 30-10, 6.

Salinas, Pedro (1998). Narraciones completas. Barcelona: Península. Reseña: CONTE, Rafael (1998). «Narraciones completas». ABC ( $A B C$ Cultural 352), 31-7, 11.

SAMPEDRO, José Luis (1995). Fronteras. Madrid: Aguilar. Reseña: GoÑI, Javier (1996) «Recuerdos de un corazón enfermo». El País (Babelia 222), 20-1, 11.

SÁNCHEZ-ORTIZ, Emilio (1997). Cuentos, historias y otros deseos insatisfechos. Madrid: Alfaguara. Reseña: SENABRE, Ricardo (1997). ABC ( $A B C$ Cultural 302), 15-8, 12.

Santiago, Elena (1998). Cuentos. Valladolid: Junta de Castilla y León. Reseña: OBIOL, María José (1998). «La infancia pensada y poseída». $E l$ País (Babelia 350), 25-7, 10.

SANTOS, Care (1996). Intemperie. Alcalá de Henares: Fundación Colegio del Rey (Premio de narrativa "Ciudad de Alcalá de Henares»). Reseñas: CASTRO, Pilar (1996). «Intemperie». ABC (ABC Cultural 243), 28-6, 9. J[avier] G[OÑI] (1996). «Quince cuentos calientes, fríos o tibios». El País (Babelia 251), 17-8, 8.

SANZ, Ignacio (1995). Historias de cochinos. Zaragoza: Edelvives. Reseña: SANTOS, Care (1996). «Historias de cochinos». ABC (ABC Cultural 226), 1-3, 13. 
SANZ, Pablo (1997). Cuánto lo siento. Madrid: Huerga y Fierro. Reseña: SANTOS, Care (1997). «Cuánto lo siento». ABC (ABC Cultural 294), 20$6,11$.

SASTRE, Alfonso (1996). Historias de California. Hondarribia: Editorial Hiru. Reseña: BASANTA, Ángel (1997): «Historias de California». ABC (ABC Cultural 270), 3-1, 9.

Sorela, Pedro (1998). Ladrón de árboles. Barcelona: Ediciones del Bronce. Reseña: GoÑI, Javier (1998). «El reloj del deseo». El País (Babelia 343), 6-6, 8 .

SORIANO, Elena (1996). Tres sueños y otros cuentos. Madrid: Huerga y Fierro. Reseña: R. S. (1996). «Tres sueños y otros cuentos». El País (Babelia 237), 11-5, 10.

SUÁREZ, Gonzalo (1997). La literatura. Madrid: Alfaguara (Prólogo de Juan José Millás). Reseñas: CoNTE, Rafael (1997). «La literatura». (ABC Cultural 301), 8-8, 11. G. A. (1997). «Ejercicios de impertinencia creativa». El País (Babelia 305), 6-9, 8.

TORREs, Cipriano (1996). Hazlo cuando me cambie de bragas. Murcia: KR Editorial. Reseña: J. B. (1996). «La brutalidad de llamar las cosas por su nombre». El País (Babelia 259), 12-10, 11.

TORRES, Rafael (1996). El asesino de Sintra. Madrid: Calambur. Reseñas: R. P. (1996). «De asesinos melancólicos y espías con mala suerte». El País (Babelia 239), 25-5, 10. CASTRo, Pilar (1996). «El asesino de Sintra». $A B C$ (ABC Cultural 240), 7-6, 13.

- (1998). Ese cadáver. Madrid: Ollero \& Ramos. Reseña: De la PEÑA, Luis (1998). «Muertes ciertas en el Madrid asediado». El País (Babelia $358), 19-8,10$.

Trigo, Felipe (1998). Cuentos ingenuos. Madrid: Clan Editorial. Reseña: LONGARES, Manuel (1999). «Felipe Trigo imita a Maupassant». El País (Babelia 381), 27-2, 6.

TUSQUETS, Esther (1996). La niña lunática. Barcelona: Lumen. Reseña: Oвıо, María José (1996). «La voz de la rebelión». El País (Babelia 268), 14-12, 11.

VALENTE, José Ángel (1995). El fin de la edad de plata. Barcelona: Tusquets (Prólogo de Jacques Ancet). Reseña: NAVARRO, Justo (1996). «Valente y la realidad fantástica». El País (Babelia 221), 13-1, 11.

VAlERA, Juan (1995). Cuentos. Narraciones inacabadas. Traducciones. Teatro. Artículos. Madrid: Turner-Biblioteca Castro. Reseña: GARCÍA Gual, Carlos (1996) «El humor de Juan Valera». El País (Babelia 229), 9-3, 10. VICENT, Manuel (1997). Los mejores relatos. Madrid: Alfaguara (Prólogo de Juan Cueto). Reseñas: OBiol, José María (1997). «Navegar por los sentidos». El País (Babelia 290), 24-5, 10. MARCo, Joaquín. «Los mejores relatos». $A B C$ ( $A B C$ Cultural 294), 20-6, 10. 
VIDAL-FolCh, Ignacio (1997). Amigos que no he vuelto a ver. Barcelona: Anagrama. Reseñas: GARCÍA-PosAdA, Miguel (1997). «Sombras y caricaturas». El País (Babelia 280), 8-3, 13. BASANTA, Ángel (1997). "Amigos que no he vuelto a ver». $A B C$ (ABC Cultural 282), 28-3, 11.

VILLAR, Agustín (1995). Velar la vida y otros relatos. Badajoz: Ediciones del Oeste. Reseña: R.S. (1996). "Velar la vida y otros relatos». ABC. (ABC Cultural 218), 5-1, 8.

ZABALBEASCOA, Anatxu (1999). Lo que piensan los perros. Cáceres: Editora Regional de Extremadura. Reseña: GOÑI, Javier (1999). «Vidas constuidas». El País (Babelia 408), 11-9, 8.

ZamoRa ReBoso, José (1999). Abako (Obra completa). Tenerife: Baile del Sol (Prólogo de Isaac de Vega). Reseña: De la Peña, Luis (1999). «Todos los cuentos de Zamora Reboso» El País (Babelia 421), 11-12, 6.

ZAMORA VICENTE, Alonso (1996). Historias de viva voz. Madrid: Alianza.

Reseñas: J[avier] G[OÑ] (1996). «Monólogos y chácaras de la gente de a pie». El País (Babelia 230), 16-3, 8. Villanueva, Darío (1996). «Historias de viva voz». $A B C$ ( $A B C$ Cultural 231), 5-4, 9.

- (1998). Cuentos con gusano dentro. Palma de Mallorca: Bizoc. Reseña: J[avier] G[OÑI] (1999). «Siempre es domingo para Alonso Zamora». El País (Babelia 383), 13-3, 6.

b) Antologías

Camarena, Julio y Chevalier, Maxime (1997). Catálogo tipológico del cuento folklórico español. Cuentos de animales. Madrid: Gredos. Reseña: J. M. G. (1998). «Todos los cuentos españoles de animales». $E l$ País (Babelia 324), 17-1, 11.

VV.AA. (1995). Cuentos de este siglo. Treinta narradoras españolas contemporáneas. Barcelona: Lumen (Edición de Ángeles Encinar). Reseñas: Obiol, María José (1996). «En el nombre del cuento». El País (Babelia 221), 13-1, 11. ConTE, Rafael (1996). "Cuentos de este siglo». $A B C$ (ABC Cultural 220), 19-1, 11.

VV.AA. (1995). Trece historias breves. Madrid: Ediciones Lengua de Trapo.

Reseña: GoÑI, Javier (1996). «Lengua de Trapo apuesta por lo nuevo». El País (Babelia 223), 27-1, 8.

VV.AA. (1995). Este mundo. Diez relatos y un poema. Barcelona: Plaza \& Janés. Reseña: N. B. (1996). «Diez relatos y un poema para ayudar a tres ONG». El País (Babelia 231), 23-3, 10.

VV.AA. (1996). Madres e hijas. Barcelona: Anagrama (Edición y prólogo de Laura Freixas). Reseñas: OBIOL, María José (1996). «Una aportación 
propia». El País (Babelia 228), 2-3, 10. BASANTA, Ángel (1996). «Madres e hijas». ABC (ABC Cultural 228), 15-3, 10.

VV.AA. (1996). Relatos para el crecimiento personal. Bilbao: Desclée de Brouwer (Edición de Carlos Alemany, prólogo de José Luis Pinillos). Reseña: R. B. (1996). «Una antología como el espejo del alma». El País (Babelia 246), 13-7, 12.

VV.AA. (1996). Nuevas aventuras de Simbad el marino. Barcelona: Montesinos. Reseña: M[aría] J[osé] O[BIOL] (1996). «Doce escritores y un marino». El País (Babelia 263), 9-11, 11.

VV.AA (1997). Una infancia de escritor. Zaragoza: Xordica (Edición y prólogo de Mercedes Monmany). Reseña: Castro, Pilar (1997). «Una infancia de escritor». ABC (ABC Cultural 294), 20-6, 10.

VV.AA. (1997). Cuentos populares españoles. Madrid: Siruela (Edición de José María Guelbelzu). Reseña: PeredA, Rosa (1997). «A los cuentos populares hay que bañarlos, vestirlos y peinarlos». El País (Babelia 315), $12-11,10$.

VV.AA (1997). Proceder a sabiendas. Antología de la narrativa de vanguardia española. Barcelona: Alba (Edición de D. Ródenas). Reseña: CoNTE, Rafael (1997). «Proceder a sabiendas». $A B C$ ( $A B C$ Cultural 318), 5-12, 14.

VV.AA (1997). Páginas amarillas. Madrid: Lengua de Trapo (Introducción de Sabas Martín). Reseñas: ConTE, Rafael (1998). «Páginas amarillas». $A B C$ (ABC Cultural 322), 2-1, 11. EcheVARRÍA, Ignacio (1998). «Los herederos de la promesa». El País (Babelia 325), 24-1, 15.

VV.AA. (1997). Relatos célebres sobre la pintura. Barcelona: Altera (Edición de Daniel Arago). Reseña: FreIXAS, Laura (1998). «Palabras en torno a las imágenes». El País (Babelia 326), 31-1,10.

VV.AA (1997). Ejercicios de estilo. Oviedo: Ayuntamiento de Oviedo. Reseña: J. D-G. (1998). «Ejercicios de estilo». ABC (ABC Cultural 333), 20-3, 30.

VV.AA. (1997). Al faro. Barcelona: Ediciones Altera. Reseñas: FreIXAs, Laura (1997). «Edgar Allan Poe y compañía». El País (Babelia 287), 35, 11. R. B. (1997). «Nueve escritores concluyen un relato inacabado de Poe». El País (Babelia 275), 1-2, 13.

VV.AA. (1998). Escritores contra el racismo. Madrid: Talasa. Reseña: R. B. (1998). «Merecidas voces contra el racismo». El País (Babelia 353), $22-$ $8,10$.

VV.AA. (1998). Los cuentos que cuentan. Barcelona: Anagrama (Edición de J. A. Masoliver Ródenas y Fernando Valls). Reseñas: CASTRo, Antón (1998). «Historias que parecen de verdad». $A B C$ (ABC Cultural 359), 1510, 12. Echevarría, Ignacio (1998). «Cuentos sin cuenta». El País (Babelia 362), 17-10, 7. 
VV.AA. (1998). La mascota virtual y otros relatos. Madrid: Alfaguara (Quinto certamen «Los nuevos de Alfaguara). Reseña: R. B. (1998). «Variada cosecha de cuentos jóvenes». El País (Babelia 362), 17-10, 6. VV.AA. (1998). La narrativa breve socialista en España. Madrid: Centro de Estudios Históricos de la UGT (Edición de Luis Arias González y Francisco de Luis Martín). Reseña: R. B. (1998). «Narrativa breve para militantes». El País (Babelia 362), 17-10, 6.

VV.AA. (1998). Cien años de cuentos (1898-1998). Antología del cuento español en castellano. Madrid: Alfaguara (Selección y prólogo de José María Merino). Reseñas: EchEvarRía, Ignacio (1998). «Cuentos sin cuenta». El País (Babelia 362), 17-10, 7. CASTEJón, Encarna (1998). «El oído y la memoria». $A B C$ ( $A B C$ Cultural 363), 12-11, 11.

VV.AA. (1998). Vidas de mujer. Relatos. Madrid: Alianza (Prologo y selección de Mercedes Monmany). Reseñas: RoDríGuez Fischer, Ana (1999). «Ellas también cuentan». $A B C$ ( $A B C$ Cultural 376), 13-2, 14. MoRA, Rosa (1999). «Agudas miradas de mujer». El País (Babelia 387), 17-4, 5. VV.AA. (1999). Memoria de Iberia. Cuentos, relatos e historias sobre el mundo de los Íberos (Edición de Alicia Perea). Reseña: C[arlos] G[ARCía] G[UAL] (1999). «Antología de relatos cortos sobre los íberos». El País (Babelia 415), 30-10, 10.

VV.AA. (1999). Mujeres al alba. Madrid: Alfaguara. Reseña: MoRA, Rosa (1999). «Agudas miradas de mujer». El País (Babelia 387), 17-4, 5.

VV.AA (1999). 29 dry martinis. Barcelona: Edhasa. Reseña: ANDRESCo, Víctor (1999). «Ginebra enamorada». $A B C$ ( $A B C$ Cultural 394), 26-6, 20.

VV.AA (1999). After hours. Una muestra de Cult Fiction. Barcelona: Mondadori (Coordinación y nota previa de Javier Calvo. Advertencia de Claudio López de Lamadrid. Reportaje interior de Tina Bagué). Reseña: FonTANA, Antonio (1999). «No hay dos noches iguales». ABC (ABC Cultural 397), 4-9, 14.

VV.AA (1999). Cuentos eróticos de Navidad. Barcelona: Tusquets. Reseña: CASTRO, Antón (1999). «La Navidad y el frenesí del deseo». $A B C(A B C$ Cultural 413), 24-12, 15.

\section{Hispanoamérica}

a) Obras

Abreu, Nicolás; ABreu, José; ABreu, Juan (1998). Habanera fue. Barcelona Muchnik. Reseña: CASTRO, Antón (1999). «Cuba y la madre muerta». $A B C$ ( $A B C$ Cultural 373), 21-1, 13. 
ALLENDE, Isabel (1997). Afrodita. Cuentos, recetas y otros afrodisiacos. Barcelona: Plaza y Janés. Reseñas: MARCo, Joaquín (1997). «Afrodita. Cuentos, recetas y otros afrodisiacos». ABC (ABC Cultural 311), 17-10, 11. PEREDA, Rosa (1998). «Afrodita, en el fogón». El País (Babelia 323), 10-1, 9.

ArenAS, Reinaldo (1995). Adiós a mamá (De La Habana a Nueva York). Barcelona: Altera (Prólogo de Mario Vargas Llosa). Reseña: MARCo, Joaquín (1996). «Adiós a mamá (De La Habana a Nueva York)». ABC (ABC Cultural 220, 19-1, 13.

Arreola, Juan José (1998). Narrativa completa. Madrid: Alfaguara. Reseña: J[avier] G[OÑ] (1998). «La gran mancha del idioma». El País (Babelia 338), 2-5, 11.

Barceló, Tomás; Rivera, Juan Carlos; GutiérRez, Pedro J.; TrujLlo, Idania y SANTIESTEBAN, Elder (1997). Cuentos de la Habana vieja. Madrid: Olalla Ediciones. Reseña: S. F. (1997). «Breves referencias de la narrativa cubana actual». El País (Babelia 287), 3-5, 10.

BAYLY, Jaime (1999). Yo amo a mi mami. Barcelona: Anagrama. Reseña: MARín, Juan (1999). «El regazo de las maravillas». El País (Babelia 388), 24-4, 10.

BENEDETTI, Mario (1999). Buzón de tiempo. Madrid: Alfaguara. Reseñas: García-PosadA, Miguel (1999). «De la historia y el tiempo». El País (Babelia 410), 25-9, 11. Álvarez Garriga, Carles (1999). «A ratos, Benedetti». $A B C$ (ABC Cultural 409), 27-11-99: 14.

Bioy CASAREs, Adolfo (1998). En viaje. Barcelona: Tusquets. Reseña: J[avier] G[OÑI] (1998). «El espejo de los armarios roperos». El País (Babelia 337), 25-4, 13.

- (1998). Una magia modesta. Barcelona: Tusquets. Reseña: J[avier] G[OÑI] (1998). «El espejo de los armarios roperos». El País (Babelia 337), 25-4, 13.

Bombal, María Luisa (1998). La última niebla / La amortajada. Barcelona:

Seix Barral. Reseña: FreIXAS, Laura (1998). «Sensualidad y fantasía». El País (Babelia 361), 10-10, 6.

BOTERO, Juan Carlos (1998). Las ventanas y las voces. Barcelona: Ediciones

B. Reseña: J[avier] G[OÑI] (1998). «Fragmentos imprevistos». El País (Babelia 346), 27-6, 12.

BRYCE ECHENIQUE, Alfredo (1995). Cuentos completos. Madrid: Alfaguara.

Reseña: GARCÍA-PosAdA, Miguel (1996). «Bryce y la comedia del yo». El País (Babelia 220), 6-1, 8.

- (1999). Guía triste de París. Madrid: Alfaguara. Reseña: MARTíNEZ DE Pisón, Ignacio (1999). «Peruano en París». ABC (ABC Cultural 392), 126,31 .

Carrasco, Iván (1996). Las muertes inevitables. Barcelona: Montesinos. Reseña: SANTOS, Care (1996). «Las muertes inevitables». ABC (ABC 
Cultural 267), 13-12, 10. J. E. A[YALA] D[IP] (1997). «La parte más oscura y peligrosa de la vida». El País (Babelia 278), 22-2, 11.

Chernov, Carlos (1998). Amores brutales. Barcelona: Mondadori. Reseña: MARIGÓMEZ, Luis (1998), «Monstruos blandos». $A B C$ (ABC Cultural 365), 26-11, 9

COLLYER, Jaime (1998). Gente al acecho. Barcelona: Emecé. Reseña: GIRALT TORRENTE, Marcos (1998). «Épicas de solitarios». El País (Babelia 350), 25-7, 10.

Coloane, Francisco (1999). Cuentos completos. Madrid: Alfaguara (Prólogo de José María Guelbenzu). Reseñas: RodríGuEz-FISCHER, Ana (1999). «Épica en las Antípodas». $A B C$ ( $A B C$ Cultural 396), 10-7, 19. SATORRAS, Lluis (1999). «En el país de los hielos eternos». El País (Babelia 400), 17-7, 9 .

- (1999). Cuentos escogidos. Madrid: Ollero \& Ramos. Reseña: SATORRAS, Lluis (1999). «En el país de los hielos eternos». El País (Babelia 400), 17-7, 9.

Covadlo, Lázaro (1997). Agujeros negros. Barcelona: Altera. Reseña: M[arcos] G[IRALT]-T[ORRENTE] (1998). «Doce cuentos sobresalientes». El País (Babelia 337), 25-4, 12.

DARío, Rubén (1997). Cuentos. Madrid: Cátedra (Introducción de José M. ${ }^{\mathrm{a}}$ Martínez). Reseña: GarCía MARTín, J. L. (1997). «Cuentos». ABC (ABC Cultural 314), 7-11, 26.

DenEvi, Marco (1996). Ceremonias secretas. Madrid: Alianza. Reseña: M[arcos] G[IRALT]-T[ORRENTE] (1997). «Una selección de los cuentos de Marco Denevi». El País (Babelia 278), 22-2, 10. Cruz VARela; María Elena (1997). «Ceremonias secretas». $A B C$ ( $A B C$ Cultural 293), 13-6, 10.

- (1999). Falsificaciones y otros relatos. Cádiz: Ediciones Corregidor. Reseña: AyalA-DIP, J. Ernesto (1999). «Cuentos irónicos desde Buenos Aires». El País (Babelia 401), 24-7, 8.

EhrenHAuS, Andrés (1997). Monogatari. Barcelona: Mondadori. Reseña: AYALA-DIP, J. Ernesto (1997). «El ingenio de Andrés Ehrenhaus». El País (Babelia 299), 26-7, 11.

EstÉvez, Abilio (1998). El horizonte y otros regresos. Barcelona: Tusquets. Reseña: MARTíNEZ DE PISÓN, Ignacio (1998). «El totalitarismo y sus fábulas». $A B C$ ( $A B C$ Cultural 362), 5-11, 12. GARCía-PosadA, Miguel (1998). «Más allá de los límites». El País (Babelia 367), 2111,9 .

FernándeZ, Pablo Armando (1998). El talismán y otras evocaciones.

Madrid: Libertarias. Reseña: J[avier] G[OÑI] (1999). «Una casa, una flor y un nacimiento». El País (Babelia 373), 2-1, 9.

FoGWILl, Rodolfo Enrique (1998). Cantos de marineros en La Pampa. Bar- 
celona: Mondadori. Reseña: EchEVARRÍA, Ignacio.(1998). «Escribir para no ser escrito». El País (Babelia 344), 13-6, 11.

FonseCA SIOSI, Cristóbal (1996). Isoty el viejo y otros cuentos. Madrid: Editorial Medio Ambiente. Reseña: R. S. (1996). «La convivencia de lo ordinario y lo fantástico». El País (Babelia 237), 11-5, 10.

FUENTES, Carlos (1996). La frontera de cristal. Madrid: Alfaguara. Reseñas: MARCO, Joaquín (1996). "La frontera de cristal». ABC (ABC Cultural 236), 10-5, 7. M[iguel] G[ARCíA]-P[OSADA] (1996). «El poderío épico de Carlos Fuentes». El País (Babelia 238), 18-5, 9.

Gómez Valderrama, Pedro (1997). Cuentos completos. Madrid: Alfaguara. Reseña: J[avier] G[oÑI] (1998). «La gran mancha del idioma». El País (Babelia 338), 2-5, 11.

GonZÁleZ LEÓN, Adriano (1998). Todos los cuentos más uno. Madrid: Alfaguara. Reseña: AYALA-DIP, J. Ernesto (1998). «De la imaginación a la pedagogía». El País (Babelia 362), 17-10, 6.

Granados, Tomás (1996). Olvidos memorables. Barcelona: Montesinos.

Reseñas: SANTOS, Care (1996). «Olvidos memorables». $A B C$ ( $A B C C u l$ tural 241), 14-6, 9 I. D. I. P. (1996). «Una relación erótica y onírica con la realidad». El País (Babelia 261), 26-11, 10.

GutiérReZ, Pedro Juan (1998). Trilogía sucia de La Habana. Barcelona: Anagrama. Reseña: GARCíA-PoSADA, Miguel (1998). «En el reino del fango». El País (Babelia 363), 24-10, 6.

JACOBS, Bárbara (1996). Doce cuentos en contra. Madrid: Ediciones La Palma. Reseña: DE LA PEÑA, Luis (1996). «Orígenes narrativos de Bárbara Jacobs». El País (Babelia 246), 13-8, 13.

LeZAMA Lima, José (1999). Relatos. Madrid: Alianza. Reseñas: Ayala-DiP, J. Ernesto (1999). «La ética de la cultura en Lezama Lima». El País (Babelia 402), 31-7, 5. CASTro, Antón (1999). «El poeta y la alquimia verbal». $A B C$ ( $A B C$ Cultural 409), 27-11-99: 15.

LugonES, Leopoldo (1999). La lluvia de fuego. Madrid: Ediciones Internacionales Universitarias. Reseña: J. E. A[YALA] D[IP] (1999). «Cuentos de terror y fantasía». El País (Babelia 388), 24-4, 8.

Monterrosso, Augusto (1996). Cuentos, fábulas y lo demás es silencio. México: Alfaguara. Reseña: García-PosADA, Miguel (1996). «Monterroso, la tristeza del humor». El País (Babelia 237), 11-5, 11.

- (1999). Antología personal. Madrid: Visor (con CD-ROM). Reseñas: J[avier] G[OÑI] (1999). «Monterroso lee lo del dinosaurio». El País (Babelia 396), 19-6, 11. ORTEGA, Antonio (1999). «Monterroso, la vida». $A B C$ (ABC Cultural 395), 3-7, 11.

NAvARro, Hipólito G. (1996). El aburrimiento, Lester. Madrid: Anaya \& Mario Muchnik. Reseña: SANTOS, Care (1997). «El aburrimiento, Lester». $A B C$ (ABC Cultural 277), 21-2, 10. 
Orellana MoRA, Jorge (1998). Cuentos \& episodios. Madrid: Sial. Reseña: R. B. (1998). «Una visión caleidoscópica de Chile». El País (Babelia 365), 7-11, 12.

PERI RossI, Cristina (1997). Desastres íntimos. Barcelona: Lumen. Reseña: FuERTES, Sol (1997). «Los deseos y placeres más íntimos». El País (Babelia 284), 12-4, 8.

PIÉROlA, José de (1999). En el vientre de la noche. Valencia: Pre-Textos (XII Premio Internacional de Cuentos Max $A u b$ ). Reseña: J[avier] G[OÑI] (1999). «El último premio de cuentos Max Aub». El País (Babelia 407), 4-9, 8.

Posadas, Carmen (1997). Nada es lo que parece. Madrid: Alfaguara. Reseña: NoRIEGA, J. L. (1998). «Nada es lo que parece». $A B C$ ( $A B C$ Cultural 324), 16-1, 24.

RAMíREZ, Sergio (1998). Cuentos completos: México: Alfaguara. Reseña: AYALA-DIP, J. Ernesto (1998). «De la imaginación a la pedagogía». El País (Babelia 362), 17-10, 6.

RetJMAN, Martín (1999). Velcro y yo. Madrid: Lengua de Trapo. Reseñas: MarTínez de Pisón, L. (1999). «Martín Rejtman. Velcro y yo». $A B C$ ( $A B C$ Cultural 391), 5-6, 25. J. E[rnesto] A[YALA]-D[IP] (1999). «Seis relatos del escritor argentino Martín Retjman». El País (Babelia 400), 7-7, 8.

REY RosA, Rodrigo (1998). Ningún lugar sagrado. Barcelona: Seix Barral. Reseña: SuÑÉn, Juan Carlos (1998). «Lo que esconden las voces». $A B C$ (ABC Cultural 367), 10-12, 14.

RiBEYRO, Julio Ramón (1998). Silvio en el Rosedal. Barcelona: Plaza y Janés (Colección «Relatos» dirigida por Ana María Moix). Reseña: Pujol, Carlos (1998). «Trayectos cortos». $A B C$ ( $A B C$ Cultural 356), 24-9, 14.

- (1998). Cuentos (Antología). Madrid: Espasa (Edición de Ángel Esteban). Reseña: MARTÍNEZ DE PIsón, Ignacio (1998). «Un nuevo clásico». $A B C$ (ABC Cultural 370), 31-12, 13.

Rossi, Alejandro (1997). La fábula de las regiones. Barcelona: Anagrama. Reseña: EchEVARRÍA, Ignacio (1997). «La memoria de los héroes». El País (Babelia 290), 24-5, 11.

- (1997). Manual del distraído. Barcelona: Anagrama (prólogos de J. Campos, A. Castañón, C. Monsivais, Octavio Paz y J. Villoro). Reseña: MARCO, Joaquín (1997). «Manual del distraído». $A B C$ ( $A B C$ Cultural 301), 8-8, 12.

SAlAS, Roger (1998). Ahora que me voy. Madrid: Libros del Alma. Reseña: I. L. (1999). «Locas de pasión». El País (Babelia 378), 6-2, 8.

SEPúlVEDA, Luis (1997). Desencuentros. Barcelona: Tusquets. Reseñas: GoÑI, Javier (1997). «El territorio de la imaginación». El País (Babelia 294), 21-6. 12 y J[avier] G[OÑI] (1997). «Desencuentros». El País (Babelia 291), 31-5, 4 . 
SERRANO, Enrique (1999). La marca de España. Barcelona: Destino. Reseña: DE PRADA, Juan Manuel (1999). «Una nueva Hispanidad». $A B C$ ( $A B C$ Cultural 389), 22-5, 14.

UgarTe, Pedro (1996). La isla de Komodo. Vitoria: Bassarai. Reseña: PeredA, Rosa (1996). «Miserias cotidianas». El País (Babelia 255), 14-9, 12.

VALDÉs, Zoé (1998). Traficantes de belleza. Barcelona: Planeta. Reseñas: García-Posadas, Miguel (1998). «Cuentos de Cuba y el mundo». El País (Babelia 347), 4-7, 12. Hernanz, Beatriz (1998). «Fabricantes de belleza». $A B C$ ( $A B C$ Cultural 351), 24-7, 13.

VAlenzuela, Luisa (1997). Simetrías. Barcelona. Plaza y Janés. Reseña: SANTOS, Care (1997). «Simetrias». ABC (ABC Cultural 291), 30-5, 10.

\section{b) Antologías}

CHERnov, Carlos (1998). Amores brutales. Barcelona: Mondadori. Reseña: J. E[mesto] A[YALA]-D[IP] (1998). «Las buenas ideas de Carlos Chernov». El País (Babelia 372), 26-12, 8.

ReY RoSA, Rodrigo (1998). Ningún lugar sagrado. Barcelona: Seix-Barral. Reseña: ECHEVARRÍA, Ignacio (1998). «Nueve relatos neoyorquinos». El País (Babelia 368), 28-11, 5.

VV.AA. (1996). Cuentos desde La Habana. Alicante: Aguaclara (Selección y prólogo de Felipe Mauri Sierra). Reseña: M[arcos] G[IRALT]T[ORRENTE] (1996). «La rica tradición cuentística cubana». El País (Babelia 250), 10-8, 15.

VV.AA. (1996). La isla contada. San Sebastián: Gakoa Liburuak (Prólogo de M. Vázquez Montalbán). Reseña: M[arcos] G[IRALT]-T[ORRENTE] (1996). «Antología del nuevo cuento cubano». El País (Babelia 234), 20-4, 11.

VV.AA. (1997). El cuento hispanoamericano en el siglo XX. Madrid: Castalia (Edición de Fernando Burgos, tres tomos). Reseñas: BEAUMONT, José F. (1997). «El cuento como desafío». El País (Babelia 300), 2-8, 8. MARCO, Joaquín (1997). «El cuento hispanoamericano en el siglo XX». $A B C$ (ABC Cultural 303), 22-8, 7.

VV.AA. (1998). Dos veces cuento. Madrid: Internacionales Universitarias (Edición de José Luis González). Reseña: M[arcos] G[IRALT]-T[ORRENTE] (1999). «La simple fuerza de la brevedad». El País (Babelia 383), 13-3, 7. VV.AA. (1999). Cuento y novela corta en España. Barcelona: Crítica (Edición de María Jesús Lacarra, prólogo de Maxime Chevalier). Reseña: G. V. (1999). «Las mil y una caras del cuento medieval». El País (Babelia 411), 2-10, 7.

VV.AA. (1999). Cuentos indígenas de América del Sur. Madrid: Miraguano (Edición de Aroní Yanko). Reseña: M[arcos] G[IRALT]-T[ORRENTE] (1999). «Cuentos de los Andes y el Amazonas». El País (Babelia 384), 20-3, 5. 
VV.AA. (1999). Líneas aéreas. Madrid: Lengua de Trapo (Edición y prólogo de Eduardo Becerra). Reseñas: CASTRO, Antón (1999). «Contra el realismo mágico». $A B C$ ( $A B C$ Cultural 387), 8-5, 9. ECHEVARRf́, Ignacio (1999). «Pájaros y aviones». El País (Babelia 398), 3-7, 6.

VV.AA (1999). Buenos Aires. Una antología de narrativa argentina. Barcelona: Anagrama (Selección y prólogo de Juan Forn). Reseña: RoDRíGUEZ SANTOS, C. (1999). «Buenos Aires. Una antología de narrativa argentina». $A B C$ (ABC Cultural 396), 10-6, 23.

\section{Autores españoles e hispanoamericanos}

VV.AA. (1996). McOndo. Barcelona: Mondadori (Edición de Alberto Fuguet y Sergio Gómez). Reseña: ECHEVARRíA, Ignacio (1997). «El estilo internacional». El País (Babelia 273), 18-1, 9.

VV.AA (1997). Cuentos de cine. Madrid: Alfaguara (Selección y prólogo de José Luis Borau). Reseña: VílloRA, Pedro Manuel (1997). «Cuentos de cine». $A B C$ ( $A B C$ Cultural 276), 14-2, 10.

VV.AA. (1998). Gentes del 98. Barcelona: Plaza \& Janés (Edición de Elena Buitragueño y Javier Goñi). Reseña: DE LA PEÑA, Luis (1999). «Cuentos sobre el 98». El País (Babelia 374), 9-1, 9.

VV.AA. (1999). 10 relatos históricos. Madrid: Auryn. Reseña: W. M. S. (1999). «Bitácora de la historia entre España y América» El País (Babelia 416), 6-11, 10.

\section{Autores angloargentinos}

Hudson, William H. (1999). El ombú. Madrid: Ediciones Internaciones Universitarias. Reseña: AYALA-Dip, J. Ernesto (1999). «El hombre que amaba a los pájaros». El País (Babelia 409), 18-9, 8.

\section{TRADUCCIONES}

\section{Otras lenguas nacionales de España}

\subsection{Catalán}

ESPAÑol, Piti (1998). Disculpen las molestias. Barcelona: Ediciones del Bronce (Traducción de M. Serrat Crespo). Reseña: SANTos, Care (1998). «Disculpen las molestias». ABC (ABC Cultural 342), 22-5, 14. 
MonCADA, Jesús (1996). Historias de la mano izquierda. Zaragoza: Xordica. (Traducción de Chusé Raúl Usón). Reseña: GoÑI, Javier (1996). «Un pueblo de humos y nieblas». El País (Babelia 243), 22-6, 10.

MonZó, Quim (1997). Guadalajara. Barcelona: Anagrama. Reseña: PerEDA, Rosa (1997). «Monzó y su colección de perdedores». El País (Babelia 302), 16-8, 8.

PÀMIES, Sergi (1998). La gran novela sobre Barcelona. Barcelona: Anagrama

(Traducción de Javier Cercas). Reseñas: SUÑÉN, Juan Carlos (1998). «La madeja en las manos». ABC (ABC Cultural 360),22-10, 12. PEREDA, Rosa (1998). «La ciudad y la trampa». El País (Babelia 362), 17-10, 6.

RIERA, Miguel Ángel (1996). Crónica lasciva de una decadencia. Barcelona: Destino (Traducción de Roser Vallés). Reseñas: GARCíA-PosADA, Miguel (1996). «De mandriles y transplantados». El País (Babelia 262), 2-11, 9. CONTE, Rafael (1996). «Crónica lasciva de una decadencia». $A B C$ ( $A B C$ Cultural 266), 6-12, 10.

Simó, Isabel Clara (1999). Mujeres. Madrid: Alfaguara (Traducción de Javier Pérez Escohotado). Reseña: DE LA PEÑA, Luis (1999). «Retratos costumbristas con mujeres». El País (Babelia 377), 30-1, 7.

\subsection{Gallego}

FolE, Ánxel (1997). De cómo me encontré con el demonio en Vigo. Madrid: Trama Editorial (Selección y traducción de Miguel Hernández Sola). Reseña: J[avier] G[OÑI] (1998). «Las inquietantes humoradas de Ángel Fole». El País (Babelia 335), 4-4, 12.

Méndez FerRín, X. L. (1997). Percival en su bosque. Madrid: Alianza (Traducción de M. Fuentes Arias). Reseña: BASANTA, Ángel (1997). «Percival en su bosque». $A B C$ ( $A B C$ Cultural 300), 1-8, 10.

- (1999). Crónica de nosotros. Zaragoza. Xordica (Traducción de Celina Suso Pasquier). Reseña: CASTRo, Antón (1999). «El señor de Tagen Ata». $A B C$ ( $A B C$ Cultural 386), 1-5, 20.

- (1999). Fría hortensia y otros cuentos. Madrid: Alianza (Varios traductores). Reseña: J[avier] G[OÑI] (1999). «Entre fantasía absoluta y realidad cruel». El País (Babelia 397), 26-6, 6.

RIVAS, Manuel (1996). ¿Qué me quieres amor? Madrid: Alfaguara (Traducción de Dolores Vilavedra). Reseñas: MARTín GARZo, Gustavo (1996). «Crónicas de un pueblo de soñadores». El País (Babelia 243), 22-6, 10. SENABRE, Ricardo (1996). «¿Qué me quieres amor?». ABC (ABC Cultural 244), 5-7, 11.

- (1999). Ella, maldita alma. Madrid: Alfaguara (Traducción y notas de Dolores Vilavedra). Reseñas: GARCíA-PoSADA, Miguel (1999). «La poesía 
del relato». El País (Babelia 415), 30-10, 6. CASTRO, Antón (1999). «El paisaje, el enigma y la lluvia». $A B C$ ( $A B C$ Cultural 406), 6-11-99: 17.

\section{Las lenguas más traducidas}

\subsection{Alemán}

a) Obras

Benjamin, Walter (1997). Parábola del desertor. Barcelona: Península (Traducción de Gonzalo Hernández Ortega). Reseña: Pujol, Carlos (1997). «Parábola del desertor». ABC (ABC Cultural 310), 10-10, 12.

- (1997). Historias y relatos. Barcelona: Península (Traducción de G. Hernández Ortega). Reseña: SILES, Jaime (1997). «Historias y relatos». $A B C$ (ABC Cultural 319), 12-12, 19.

BERNHARD, Thomas (1997). Acontecimientos y relatos. Madrid: Alianza (Traducción de Miguel Sáenz). Reseñas: SÁNCHEZ-OsTIZ, Miguel (1997). «Acontecimientos y relatos». ABC (ABC Cultural 283), 4-4, 13. ORTEGA, Carlos (1997). «Bernhard, habitante de una anomalía». El País (Babelia 283), 5-4, 11.

GRIMM, Jacob y Wilhelm (1998). Cuentos. Madrid: Alianza (Antología y traducción de Pedro Gálvez). Reseña: R. B. (1998). «Cincuenta cuentos de los hermanos Grimm». El País (Babelia 364), 31-10, 7.

HeBEL, Johann Peter (1998). Cofrecillo de joyas. Barcelona: Alba (Traducción de Antón Dieterich). Reseña: DE JUAN, José Luis (1999). «Una catedral de narradores». El País (Babelia 376), 23-1, 6.

Hesse, Hermann (1999). Cuentos de amor. Barcelona: Muchnik (Traducción de Esther Capdevila). Reseñas: DREYMüLlER, Cecilia (1999). «El eterno enamorado». $A B C$ ( $A B C$ Cultural 397), 4-9, 7. DE LA PEÑA, J. (1999). «El amor, en los personajes de Hesse». El País (Babelia 414), 23-10, 8.

KAFKA, Franz (1997). La metamorfosis y otros relatos. Barcelona: Vicens Vives (Traducción de Eustaquio Barjau). Reseña: J[avier] G[OÑ] (1997). «Nada más que un clásico contemporáneo». El País (Babelia 299), 26-7, 7.

KELLER, Gottfried (1996). La gente de Seldwyla. Madrid: Cátedra (Traducción de Isabel Hernández). Reseña: M[arcos] G[IRALT]-T[ORRENTE] (1996). «Entre el romanticismo y el realismo». El País (Babelia 264), 1611,16 .

- (1997). La gente de Seldwyla. Madrid: Cátedra (Traducción de Gonzalo Tamames). Reseña: De JuAN, José Luis (1997). «Raíces suizas». El País (Babelia 288), 10-5, 10. 
LEBERT, Hans (1996). Un barco de montaña. Barcelona: Muchnik (Traducción de Adam Novacsics). Reseña: Guelbenzu, José María (1996). «Lebert muestra los rostros del miedo». El País (Babelia 239), 25-5, 13.

RILKE, Rainer Maria (1997). A lo largo de la vida. Barcelona: Alba Editorial (Traducción de Anton Dietrich). Reseñas: Pujol, Carlos (1997). "A lo largo de la vida». $A B C$ (ABC Cultural 281), 21-3, 13. ECHEVARRíA, Ignacio (1997). «El joven Rilke». El País (Babelia 282), 22-3, 14.

- (1999). Relatos de Praga. Barcelona: Montesinos (Traducción de Lina Anguera). Reseña: ECHEGOYEN, Ana (1999). «La Praga de Rilke». $A B C$ (ABC Cultural 411), 11-12-99: 10.

SüSKIND, Patrick (1996). Un combate y otros relatos. Barcelona: Seix Barral (Traducción de Ana María de la Fuente). Reseñas: FernándeZ, Daniel (1996). «Süskind y la sombra de la duda». El País (Babelia 235), 27-4, 10. HeRnANZ, Beatriz (1996). ABC (ABC Cultural 243), 28-6, 11.

Von DROSTE-HülShOFF, Annette (1996). El haya de los judios y Ledwina. Madrid: Cátedra (Edición de Ana Isabel Almendral). Reseña: PuJoL, Carlos (1997). "El haya de los judios y Ledwina». ABC (ABC Cultural 270), 3-1, 12.

VON GOETHE, Johann Wolfgang (1999). La serpiente verde. Barcelona: Herder (Traducción de Ángela Ackermann). Reseña: I. L. (1999). «Un cuento preciosista de Goethe». El País (Babelia 390), 8-5, 9.

b) Antologías

VV.AA. (1995). Praga mágica. Barcelona: Juventud (Traducción de Herminia Dauer). Reseña: J. E[rnesto] A[YALA]-D[IP] (1996). «Itinerarios literarios por una ciudad mágica». El País (Babelia 220), 6-1, 12.

\subsection{Francés}

Camus, Albert (1996). Obras completas. Madrid: Alianza (Traducción de Manuel de Lope, Miguel Salabert, Emma Calatayud y Aurora Bernárdez). Reseña: EchevarRía, Ignacio (1997). «Camus contra Camus». $E l$ País (Babelia 280), 1-2, 13.

ERCKMANN, Emile y CHATRIAN, Alexander (1999). Hugo el lobo y otros relatos de terror. Madrid: Valdemar (Traducción de Adalberto Aguilar). Reseñas: MoReno Claros, Luis Fernando (1999). «Terror clásico del siglo XIX». $A B C$ ( $A B C$ Cultural 387), 8-5, 14. M[arcos] G[IRALT]T[ORRENTE] (1999). «Relatos decimonónicos de terror». El País (Babelia 404), 14-8, 6. 
Flaubert, Gustave (1998). Un alma de Dios. Barcelona: Plaza y Janés (Colección «Relatos» dirigida por Ana María Moix). Reseña: Pujol, Carlos (1998). «Trayectos cortos». ABC (ABC Cultural 356), 24-9, 14.

- (1998). Tres cuentos. Madrid: Alianza (Traducción de Mauro Armiño). Reseña: R. B. (1998). «Gustave Flaubert, maestro del relato». El País (Babelia 362), 17-10, 7.

GAUTIER, Théophile (1999). Muertas enamoradas. Barcelona: Lumen (Edición y traducción de Marta Giné). Reseña: DE JUAN, José Luis (1999). «La mujer y lo fantástico». El País (Babelia 418), 20-11, 6.

LA FonTAINE, Jean (1995). Cien fábulas. Madrid: Guillermo Blázquez Editor, Edición especial para Privanza. Reseña: Solana, Guillermo (1996). «Cien fábulas». $A B C$ (ABC Cultural 230), 29-3, 11.

Loti, Pierre (1998). Japón en otoño. Barcelona: Abraxas (Traducción de Vicente Clavel). Reseña: E. P. (1999). «El Japón contado por Loti, el impenitente viajero». El País (Babelia 376), 23-1, 6.

MallarmÉ, Stéphane (1995). Cuentos indios. Valencia: Pre-Textos (Traducción de Xavier Aleixandre). Reseña: M[arcos] G[IRALT]-T[ORRENTE] (1996). «Cuatro cuentos indios de Mallarmé». El País (Babelia 227), 24-2, 11.

SAND, George (1998). Cuentos de una abuela. Madrid: Trama (Traducción de Amaya García Gallego). Reseñas: CASTEJón. Encarna (1999). «Deformaciones». ABC (ABC Cultural 375), 4-2, 12. PEREDA, Rosa (1999). «Cuentos de hadas para una niña libre». El País (Babelia 381), 27-2, 12.

ScHwoB, Marcel (1998). Dos cuentos latinos. Barcelona: Muchnik (Traducción de Mauricio Wácquez). Reseña: CASTRO, Antón (1999). «El maestro, la tumba y Margarita». $A B C$ ( $A B C$ Cultural 371), 7-1, 12.

Semprún Maura, Carlos (1997). Polvo de líneas. Valencia: Pre-Textos (Traducción de Julia Escobar). Reseña: BASANTA, Ángel (1998). «Polvo de líneas». $A B C$ (ABC Cultural 326), 30-1, 14.

TOPOR, Roland (1996). Acostarse con la reina. Barcelona: Anagrama Reseña: Berlanga, Jorge (1996). ABC (ABC Cultural 252), 30-8, 12. VolTAIRE (Seudónimo de François Marie Arouet) (1999). El ingenuo y otros cuentos. Madrid: Espasa Calpe (Traducción y edición de Mauro Armiño). Reseña: (1999). «El ingenuo y otros cuentos». ABC (ABC Cultural 382), 27-3, 26.

\subsection{Inglés}

a) Obras

ADAMs, Richard (1998). Cuentos de la colina de Watership. Barcelona: Seix Barral (Traducción de Encarna Quijana). Reseña: DE JuAN, José Luis (1998). «Waterloo de conejos». El País (Babelia 344), 13-6, 9. 
AMIs, Martin (1999). Mar gruesa. Barcelona: Anagrama (Traducción de Jesús Zulaika). Reseña: CASTANEDo, Fernando (1999). «Cuentos salados». $A B C$ ( $A B C$ Cultural 398), 11-9, 20.

ATwood, Margaret (1998). Chicas bailarinas. Barcelona: Lumen (Traducción de Víctor Pozanco). Reseñas: ORTEGA, Carlos «El problema de ellas». ABC (ABC Cultural 354), 10-9, 11. MonMANY, Mercedes (1998). «La asesina de dieciséis años». El País (Babelia 365), 7-11, 10.

- (1999). Asesinato en la oscuridad. Oviedo: KRK Ediciones (Traducción y epílogo de Isabel Carrera Suárez). Reseña: Monmany, Mercedes (1999). «Un planeta a la deriva». El País (Babelia 395), 12-6, 8.

BARNES, Julian (1997). Al otro lado del canal. Barcelona: Anagrama (Traducción de Carmen Franci y Juan Gabriel López Guix). Reseñas: VILAMATAS, Enrique (1997). «En el canal de Julian Barnes». El País (Babelia 283), 5-4, 16. Pujol, Carlos (1997). "Al otro lado del canal». $A B C$ ( $A B C$ Cultural 290), 23-5, 11.

BeCKETT, Samuel (1997). Relatos. Barcelona: Tusquets (Traducciones de Félix de Azúa, Ana María Moix y Jenaro Talens). Reseña: J. A. R. (1997). «Los relatos de Beckett: píldoras de puro vacío». El País (Babelia 309), 4-10, 9.

BradBuRY, Ray (1998). Mucho después de medianoche. Barcelona: Minotauro (Traducción de Marcial Souto). Reseña: GuElBENZU, José María (1998). «Ray Bradbury, un maestro del ingenio». El País (Babelia 352), 8-8, 11.

BurRoughs, William S. (1997). Mi educación: un libro de sueños. Barcelona: Península (Traducción de J. M. Álvarez Flórez). Reseña: GuRPEGUI, José Antonio (1997). «Mi educación: Un libro de sueños». $A B C(A B C$ Cultural 319), 12-12, 20.

CANIN, Ethan (1996). El ladrón de palacio. Barcelona: Anagrama (Traducción de Javier Calzada). Reseñas: GuRPEGUI, José Antonio (1997). «El ladrón de palacio». $A B C$ ( $A B C$ Cultural 272), 17-1, 12. AyAlA-DIP, J. Emesto (1997). «La impostura de Ethan Canin». El País (Babelia 280), 8-3, 10.

- (1999). El emperador del aire. Barcelona: Emecé (Traducción de Carmen Francí Ventosa). Reseña: GiRAlt-ToRRENTE, Marcos (1999). «Instantes de clarividencia». El País (Babelia 389), 1-5, 12.

CANTY, Kevin (1998). Ajenos a este mundo. Barcelona: Emecé (Traducción de Mariano Antolín Rato). Reseña: MARÍN, Juan (1998). «El desconcierto de los inocentes». El País (Babelia 333), 21-3, 14.

CAPOTE, Truman (1998). Tres cuentos. Barcelona: Anagrama (Traducción de E. Murillo, P. Brines y Á. Pérez). Reseñas: IBÁÑEZ, Andrés (1998). «Fría infancia feliz». $A B C$ ( $A B C$ Cultural 368), 17-12, 23. GuElBENZU, José María (1999). «Destello de talento de Truman Capote». El País (Babelia 373), 2-1, 9. 
CARTER, Angela (1999). Fuegos de artificio. Barcelona: Minotauro (Traducción de Matilde Horne) Reseña: M[aría] J[osé] O[BIOL] (1999). «Relatos para contar entre susurros» El País (Babelia 419), 27- 11, 7.

ChATwIN, Bruce (1997). Anatomía de la inquietud. Madrid: Anaya \& Mario Muchnik (No se menciona el traductor). Reseña: MANRIQue, Diego A. (1997). «La estética nómada de Bruce Chatwin». El País (Babelia 280), $1-3,8$.

Chesterton, G. K. (1999). Las parodias de Mr. Pond. Madrid: Valdemar (Traducción de F. Jadraque y M. Trouillhet). Reseña: GuELBENZU, José María (1999). «Chesterton o el arte de la paradoja». El País (Babelia 404), 14-9, 7.

CHRISTIE, Agatha (1998). Un dios solitario. Barcelona: Plaza y Janés (Traducción de C. Milla Soler). Reseña: PUJOL, Carlos (1998). «Un dios solitario». $A B C$ ( $A B C$ Cultural 350), 17-7, 14.

COEN, Ethan (1998). Las puertas del Edén. Barcelona: Emecé (Traducción de Jaime Zulaika Goicoechea). Reseñas: MARIGóMEZ, Luis (1998). «Miradas dentro y fuera». $A B C$ ( $A B C$ Cultural 362), 5-11, 20. PRADO, Benjamín (1999). «Lo dos Ethan Coen». El País (Babelia 377), 30-1, 12.

CONAN DoYle, Arthur (1996). Cuentos de terror y misterio. Madrid: Alfaguara (Traducción de Amando Lázaro Ros). Reseña: R. B. (1997). «Los estupendos relatos de Arthur Conan Doyle». El País (Babelia 274), 25-1, 7.

Coover, Robert (s.d). El hurón mágico. Barcelona: Anagrama (Traducción de J. A. Masoliver). Reseña: GuRPEGUI, José Antonio (1998). «Zarzarrosa». $A B C$ (ABC Cultural 347), 26-6, 20.

COSSERY, Albert (1996). Los nombres olvidados de Dios. Madrid: Anaya \& Mario Muchnik (Traducción de Mauricio Vázquez). Reseña: M[arcos] G[IRALT]-T[ORRENTE] (1996). «Cinco cuentos de Albert Cossery». El País (Babelia 260), 19-10, 10.

Coupland, Douglas (1999). Polaroids. Barcelona: Ediciones B. Reseña: Romeo, Félix (1999). «Collages para el Apocalipsis». ABC (ABC Cultural 384), 17-4, 12.

CRANE, Stephen (1997). El monstruo. Barcelona: Alba (Traducción de Aurelio Martínez a excepción de «Un episodio de guerra», traducido por Luis Magrinyá). Reseña: CuENCA, Luis Alberto de (1997). «El monstruo». $A B C$ (ABC Cultural 315), 14-11, 19.

CROWLEY, John (1995). Antigüedades. Barcelona: Minotauro (Traducción de Matilde Horne). Reseña: CuENCA, Luis Alberto de (1996). «Antigüedades». ABC (ABC Cultural 219), 12-1, 12.

DANTICAT, Edwidge (1999). ¿Krik? ¡Krak!. Barcelona: Lumen (Traducción de Ramón González Férriz). Reseña: ANDRESCO, Víctor (1999). «Estrellas en los ojos». $A B C$ ( $A B C$ Cultural 406), 6-11-99: 19.

DíAZ, Junot (1996). Los boys. Barcelona: Mondadori (Traducción de Miguel 
Martínez-Lage). Reseña: EchEVARRÍA, Ignacio (1997). «Los merengues sucios de Junot Díaz». El País (Babelia 272), 11-1, 13.

DiCKENS, Charles (1998). Acorralado y otros cuentos. Barcelona: Península

(Traducción de Ana Poljak). Reseña: Pujol, Carlos (1999). «Dickens al por menor». $A B C$ ( $A B C$ Cultural 380), 13-3, 9.

Dising, Jenny (1997). Mi hermano Stanley. Barcelona: Circe. Reseña: OBIOL, María José (1997). «Transgresión y sorpresa». El País (Babelia 301), 9-8, 10.

FAULKNER, William (1996). Humo. Madrid: Alianza. (Traducción de L. Moreno). Reseña: R. B. (1996). «El orgullo, el rencor y la codicia en Faulkner». El País (Babelia 252), 24-8, 11.

FAULKNER, William (1997). Relatos. Reseña: CoNTE, Rafael (1997). «Relatos». ABC (ABC Cultural 316), 21-11, 27.

GARNER, James Finn (1997). Cuentos navideños políticamente correctos. Barcelona: Circe (Traducción de Gian Castelu). Reseña: R. B. (1997). «Una Navidad políticamente correcta». El País (Babelia 320), 20-12, 10.

HAWTHORNE, Nathaniel (1999). Cuentos de la nueva Holanda. Madrid: Ediciones Internacionales Universitarias (Traducción de F. González Vicen). Reseña: PUIG, Valentí (1999). «Tumbas y monumentos de Hawthorne». El País (Babelia 409) 18-9, 9.

Hodgson, William H. (1997). La nave abandonada. Madrid: Valdemar (Traducción de Esperanza Castro). Reseña: GuELbENZU, José María (1997). «El placer del horror». El País (Babelia 293), 14-6, 12.

IRVING, John (1997). La novia imaginaria. Barcelona: Tusquets (Traducción de Jordi Fibla). Reseñas: R. B. (1997). «La novia imaginaria». El País (Babelia 291), 31-5, 7. GURPEGUI, José Antonio (1997). «La novia imaginaria». $A B C$ (ABC Cultural 292), 6-6, 12. SATORRAS, Lluís (1997). «Un oso en la pensión de Grillparzer». El País (Babelia 295), 28-6, 9.

IRVING, Washington (1996). Cuentos de la Alhambra. Madrid: Cátedra (Edición de J. A. Gurpegui; Traducción de J. J. Santamaría y R. Marino). Reseñas: R. B. (1997). «Fascinación por las leyendas de Granada». El País (Babelia 274), 25-1, 13. Pujol, Carlos (1997). «Cuentos de la Alhambra». ABC (ABC Cultural 285), 18-4, 12.

JAMES, Henry (1999). El altar de los muertos. Madrid: Valdemar (Traducción de Fernando Jadraque). Reseña: GuElBenzu, José María (1999). «La maestría de Henry James». El País (Babelia 383), 13-3, 9.

JAMES, M. R. (1997). Corazones perdidos. Madrid: Valdemar (Traducción de Francisco Torres Oliver). Reseña: Giralt Torrente, Marcos (1998). «De fantasmas y otras criaturas». El País (Babelia 327), 7-2, 12.

JoNES, Thom (1996). El púgil en reposo. Barcelona: Muchnik (Traducción de Adán Kavacsics Meszaros). Reseña: GiRALT-ToRRENTE, Marcos (1996). «Once raptos con afán de pelea». El País (Babelia 239), 25-5, 10. 
- (1998). Ola de frío. Muchnik: Barcelona (Traducción de Adan Kovacsics). Reseña: J[uan] M[ARÍN] (1998). «Historias de amor entre el cuerpo y sus límites». El País (Babelia 334), 28-3, 10.

KIPLING, Rudyard (1999). 10 narraciones maestras. Madrid: Siruela (Traducciones de Jorge Luis Borges, Luis Magrinyá, Fernando Santos Fontenla y Jaime Zulaika). Reseña: AYAla-Dip, J. Ernesto (1999). «Antropología para andar por casa». El País (Babelia 405), 21-8, 9.

- (1999). La marca de la bestia y otros relatos fantásticos. Madrid: Valdemar (Traducciones de R. Días y C. Pereyra). Reseña: AyalA-Dip, J. Ernesto (1999). «Antropología para andar por casa». El País (Babelia 405), 21-8, 9.

KUREISHI, Hanif (1998). Amor en tiempos tristes. Barcelona: Anagrama (Traducción de Mauricio Bach). Reseñas: Solano, Francisco (1998). «Vidas desplazadas». $A B C$ ( $A B C$ Cultural 355), 17-9, 12. MARín, Juan (1998). «La década quemada». El País (Babelia 360), 3-10, 10.

LAMB, Charles y Mary (1998). Cuentos de Shakespeare. Barcelona: GrijalboMondadori (Edición de Adam Kovacsics). Reseñas: Pujol, Carlos (1998). «Shakespeare para niños». $A B C$ (ABC Cultural 358), 8-10, 6. R. B. (1998). «Los cuentos de las obras de Shakespeare». El País (Babelia 362), 17-10, 8.

LeAVITT, David (1998). Arkansas. Barcelona: Anagrama (Traducción de Juan Gabriel López Guix). Reseñas: MARIGómEZ, Luis (1998). «Magro y tocino». $A B C$ ( $A B C$ Cultural 367), 10-12, 21. PRADO, Benjamín (1999). «Historias en el fondo de una mentira». El País (Babelia 373), 2-1, 10.

Leguin, Ursula K. (1997). Cuatro caminos hacia el perdón. Barcelona: Minotauro (Traducción de Ana Quijada). Reseña: OBıol, María José (1997). «Werel y Yeowe: los otros planetas». El País (Babelia 288), 10$5,10$.

LESSING, Doris (1996). Historias de Londres. Barcelona: Destino (Traducción de María Faidella). Reseña: Pujol, Carlos (1997). «Historias de Londres». ABC (ABC Cultural 278), 28-2, 13.

- (1998). Un hombre y dos mujeres. Barcelona: Seix Barral (Traducción de Georgina Regàs). Reseña: MonMANy, Mercedes (1998). «Las heridas del amor». El País (Babelia 360), 3-10, 9.

LOVECRAFT, H. P. (1998). En la cripta. Madrid: Alianza (Traducción de Aurelio Martínez Benito, José María Aroca y Fernando Calleja). Reseña: CUENCA, Luis Alberto de (1998). «En la cripta». $A B C$ (ABC Cultural 336), 10-4, 26.

LowRY, Malcolm (1999). Escúchanos, Señor, desde el cielo tu morada. Barcelona: Tusquets (Traducción de Carlos Manzano). Reseña: VIlA-Matas, Enrique (1999). «Malcolm Lowry y el paraíso perdido». El País (Babelia 398), 3-7, 10. 
MAMET, David (1996). Una profesión de putas. Madrid: Debate (Traducción de J. M. Ibeas y J. Mustielles). Reseña: GuRPEGUI, José Antonio (1996). «Una profesión de putas». ABC (ABC Cultural 223), 9-2, 12.

- (1997). La ciudad de las patrañas. Madrid: Debate (Traducción de Juan Manuel Ibeas). Reseña: GURPEGUI, José Antonio (1997). «La ciudad de las patrañas». ABC (ABC Cultural 280), 14-3, 12.

MANSFIELD, Katherine (1998). Felicidad perfecta / El desconocido. Barcelona: Plaza y Janés (Colección «Relatos» dirigida por Ana María Moix). Reseña: PUJOL, Carlos (1998). «Trayectos cortos». ABC (ABC Cultural 356), 24-9, 14.

- (1999). Cuentos completos. Barcelona: Alba (Traducción de Clara Janés, Esther de Andreis y Francesc Parcerisas). Reseña: Solano, Francisco (1999). «Quiero ser real». $A B C$ (ABC Cultural 409), 27-11-99: 13.

MELVILLE, Herman (1996). El feliz fracaso y otros relatos. Barcelona: Altera (Traducción de Albert Solé). Reseñas: Pujol, Carlos (1997). "El feliz fracaso y otros relatos». ABC (ABC Cultural 271), 10-1, 11. GuELBENZU, José María (1997). «Los fracasos felices de Herman Melville». El País (Babelia 276), 8-2, 7.

- (1999). Benito Cereno y otros cuentos del mar. Madrid: Valdemar (Traducción de J. R. Hernández Arias). Reseña: M. R. R. (1999). «Cuentos y novelas cortas de Herman Melville». El País (Babelia 386), 10-4, 11.

MunRo, Alice (1996). Secretos a voces. Madrid: Debate (Traducción de Flora Casas). Reseña: OBIOL, María José (1996). «La pasión por el relato». El País (Babelia 251), 17-8, 9.

NABoKov, Vladimir (1996). La veneziana. Madrid: Alianza (Traducción de María i Butles de Foley). Reseña: J. E[rnesto] A[YALA]-D[IP] (1996). «Nabokov, en una nueva serie de Alianza cien». El País (Babelia 249), 3$8,9$.

Planer, Geofrey (1998). Cuentos para dormir ratones. Barcelona: Lumen (Traducción de Milena Busquets). Reseña: V. F. (1998). El País (Babelia 329), 21-2, 10.

Polidori, J. W.; Shelley, P. B.; Shelley M. W. y Lord Byron (1998). Fantasmagoriana. Barcelona: Península (Traducción de Jordi Fibla). Reseña: J[avier] G[OÑI] (1998). «Narraciones a orillas del Lago Leman». El País (Babelia 362), 17-10, 7.

Prokosh, Frederic (1997). Voces. Barcelona: Mondadori (Traducción de Andrés Bosch). Reseña: GARCíA ORTEGA, Adolfo (1997). «El mito del escritor desmitificado». El País (Babelia 320), 20-12, 10.

RENDELL, Ruth (1996). La planta carnívora y otros relatos. Barcelona: Plaza \& Janés. Reseña: R. B. (1996). «Los inquietantes relatos de Ruth Rendell». El País (Babelia 239), 25-5-96.

- (1996). Linajes de sangre. Barcelona: Grijalbo (Traducción de Ana 
Herrera). Reseña: MORA, Rosa (1997). «Buenas razones para morir y para matar». El País (Babelia 275), 1-2, 12.

RushDIE, Salman (1997). Oriente-Occidente. Barcelona: Plaza \& Janés (Traducción de Miguel Sáenz). Reseñas: DE JuAN, José Luis (1997). «Salman Rushdie: Nada como el hogar». El País (Babelia 312), 25-10, 11. VILLANUEVA, Darío (1997). «Oriente, Occidente». $A B C$ (ABC Cultural 315), 14-11, 19.

SALINGER, J. D. (1997). Nueve cuentos. Barcelona: Edhasa. Reseña: LEÓNSoTELO, T. de. (1997). «Nueve cuentos». ABC (ABC Cultural 308), 26-9, 24.

SALINGER, J. D. (1998). Levantad, carpinteros, la viga del tejado. Barcelona: Edhasa (Traducción de Aurora Bernárdez). Reseña: GuRPEGUI, José Antonio (1998). «Levantad, carpinteros, la viga del tejado». ABC ( $A B C$ Cultural 352), 31-7, 12.

SaKi (Seudónimo de Héctor Hug Munro) (1999). Crónicas de Clovis. Madrid: Valdemar (Traducción de Manuel Ortuño). Reseña: MARTínEZ DE PISÓN, Ignacio (1999). «El rosario de la aurora». $A B C$ ( $A B C$ Cultural 405), 30-10-99: 22.

SAYLOR, Steven (1998). La casa de las vestales. Barcelona: Emecé (Traducción de María Luz García de la Hoz). Reseña: C[arlos] G[ARCía] G[UAL] (1999). «Más crímenes en la Roma de Cicerón». El País (Babelia 381), 27-2, 8 .

SCHEEPERS, Riana (1998). Mujeres zulúes. Barcelona: Icaria (Edición y traducción de Cristina Goikoetxea). Reseña: M[aría] J[osé] O[BIOL] (1999). «Los cuentos de la ugogo alrededor de la lumbre». El País (Babelia 381), 27-2, 9 .

SCHIMEL, Lawrence (1998). Mi novio es un duende. Barcelona: Laerte (Traducción de Marta Pérez). Reseña: M[arcos] G[IRALT]-T[ORRENTE] (1998). «Dieciséis cuentos homosexuales». El País (Babelia 349), 18-7, 10.

SHAW, George Bernard (1998). La profesión de Cashel Byron. Barcelona: Ediciones del Bronce (Traducción de Julio Brouta). Reseña: Puig, Valentí (1999). «Lo que queda de George Bernard Shaw». El País (Babelia 376), 23-1, 6.

SHEPARD, Sam (1997). Cruzando el paraíso. Barcelona: Anagrama (Traducción de Mauricio Bach). Reseñas: PrADo, Benjamín (1997). «Las experiencias de Sam Shepard». El País (Babelia 317), 29-11, 11. GURPEGUI, José Antonio (1998). «Cruzando el paraíso». ABC (ABC Cultural 324), 16-1, 15 .

- (1998). Estados de Shock. Al norte. Lengua silenciosa. Barcelona: Anagrama (Traducción de José Aguirre). Reseña: DE JuAN, José Luis (1998). «La rabia como estímulo creativo)». El País (Babelia 349), 18-7, 9. 
SHERIDAN Le FANU, Joshep (1998). La habitación del «Dragón Volador» y otros cuentos de terror y misterio. Madrid: Valdemar (Traducción de Bernardo Moreno Carrillo). Reseña: RodRíguez SANTOS, Carmen (1998). «La emoción más antigua». $A B C$ ( $A B C$ Cultural 365), 26-11, 10

SMITH, Patti (s.d). Babel. Barcelona: Anagrama (Traducción de Antonio Escohotado). Reseña: GuRPEGUI, José Antonio (1996). ABC (ABC Cultural 258), 11-10, 12.

STEVENSON, Robert Louis (1998). La casa ideal y otros textos. Madrid: Hiperión (Traducción de Santiago R. Santerbás, María Cóndor y Antonio Iriarte Jurado). Reseña: M[arcos] G[IRALT]-T[ORRENTE] (1998). «Grandes minucias de Robert L. Stevenson». El País (Babelia 347), 4-7, 11. STOKER, Bram (1999). Muerte entre bastidores y otros cuentos macabros. Madrid: Celeste (Prólogo de Roberto Cueto. Traducción de María José Antón). Reseña: MARTínEZ DE PIsón, Ignacio (1999). «La pulsión necrófila». $A B C$ ( $A B C$ Cultural 387), 8-5, 14.

STOCKTON, Frank (1996). La colcha del gigante y otros cuentos. Barcelona: Lumen (Traducción de Marisol Dorao). Reseña: Hernanz, Beatriz (1996). «La colcha del gigante y otros relatos». $A B C$ ( $A B C$ Cultural 237), 17-5, 24.

Thomas, Dylan (1998). Hacia el comienzo. Relatos completos I. Barcelona: Mondadori (Traducción de Miguel Martínez-Lage). Reseña: SÁNCHEZOsTrz, Miguel (1998). «Árboles, pájaros y fantasmas». $A B C$ ( $A B C$ Cultural 365), 26-11, 15

UPDIKE, John (1997). Lo que queda por vivir. Barcelona: Tusquets (Traducción de María Luisa Balseiro). Reseñas: J. M. G. (1997), «Lo que queda por vivir». El País (Babelia 298), 19-7, 17. GURPEGUI, José Antonio (1997). «Lo que queda por vivir». (ABC Cultural 300), 1-8, 11. Prado, Benjamín (1997). «El desafío de adivinar el pasado». El País (Babelia $300), 2-8,7$.

VIDAL, Gore (1998). La ciudad y el pilar de sal (y siete relatos de juventud). Madrid: Anaya \& Mario Muchnik (Traducción de Richard Guggenheimer). Reseña: Molina FoIX, Vicente (1998). «Un corazón romántico bajo la hiel». El País (Babelia 338), 2-5, 9.

Wells H. G. (1997). El país de los ciegos y otros relatos. Barcelona: Península (Traducción de Javier Cercas). Reseña: J[avier] G[OÑI] (1997). «La niebla que todo lo envuelve». El País (Babelia 321), 27-12, 11.

WeLSH, Irvine (1997). Acid House. Barcelona: Anagrama (Traducción de Federico Corriente). Reseña: RoJo, José Andrés (1997). «El mundo destartalado de Irvine Welsh». El País (Babelia 289), 17-5, 12.

WHARTON, Edith (1999). La carta. Barcelona: Ediciones del Bronce (Traducción de Teresa Gómez Reus). Reseña: GuElBelzU, José María (1999). «La maestría de Edith Wharton». El País (Babelia 416), 6-11, 7. 
WhITE, Edmund (1997). Desollado vivo. Barcelona: Destino (Traducción de Albert Freixa). Reseña: J[uan] M[ARÍN] (1997). «Vivir la diferencia». $E l$ País (Babelia 280), 1-3, 12.

WILliam, William Carlos (1995). Historias de médicos. Barcelona: Montesinos (Traducción de Nuria Vilanova). Reseña: GuRPEGUI, José Antonio (1996). «Historias de médicos». ABC (ABC Cultural 218), 5-1, 11.

Williams, Tennessee (1998). La noche de la iguana y otros relatos. Barcelona: Alba (Traducción de Mariano Antolín Rato). Reseña: PRADo, Benjamín (1998). «Las reglas del deseo». El País (Babelia 353), 15-8, 9.

Wolfe, Roger (1996). Todos los monos del mundo. Sevilla: Renacimiento.

Reseña: CASTRO, Pilar (1996). «Mi corazón es una casa helada». $A B C$ (ABC Cultural 231), 5-4, 9.

\section{b) Antologías}

CHOPIN, Kate (1996). Un asunto indecoroso. Barcelona: Ediciones del Bronce (Traducción de Olivia de Miguel). Reseña: GIRALT TORRENTE, Marcos (1996). «Mujeres de Nueva Orleans». El País (Babelia 258), 5-10, 10.

GRAY, Alasdair (1995). Historias sobre todo verdaderamente inverosímiles.

Barcelona: Minotauro (Traducción de Marcelo Cohen). Reseña: AYALADiP, J. Ernesto (1996). «Madera kafkiana de la mejor». El País (Babelia 230), 16-3, 8.

VV.AA. (1996). Cuentos populares británicos. Madrid: Siruela (Edición de Katharine M. Briggs; traducción de Juan Antonio Molina Foix). Reseña: R. B. (1996) «Cuentos, fábulas y leyendas británicas». El País (Babelia 243), 22-6, 12.

VV.AA. (1997). Libro del amor y de la pérdida (historias del corazón). Barcelona: Lumen (Edición de Georgina Hammick; traducción de Enrique Ibáñez). Reseña: FrEIXAS, Laura (1997). «Desgracias femeninas». El País (Babelia 285) 19-4, 8.

VV.AA. (1997). Malignos y macabros. Barcelona: Plaza y Janés (Traducción de Aguirre Oteiza). Reseña: R. B. (1997). «Veintidós relatos para tener pesadillas». El País (Babelia 316), 22-11, 13.

VV.AA. (1998). Malignos y macabros. Barcelona: Plaza y Janés. Reseña:

FONTANA, Antonio (1998). «Malignos y macabros». ABC (ABC Cultural 340), 8-5, 26.

VV.AA (1998). Fantasmagoriana. Barcelona: Península (Traducción de Jordi Fibla). Reseña: PuJol, Carlos (1998). «Una noche de terror». $A B C$ (ABC Cultural 353), 3-9, 10.

VV.AA (1999). El sudario de hierro y otros cuentos góticos. Madrid: Celeste (Prólogo de Roberto Cueto. Traducción de María José Antón). Reseña: 
MARTíNEZ DE PIsón, Ignacio (1999). «La pulsión necrófila». $A B C$ ( $A B C$ Cultural 387), 8-5, 14.

\subsection{Italiano}

a) Obras

AMICIS, Edmondo de (1999). El rey de las muñecas. Miguel Menéndez. Barcelona: Plaza y Janés (Traducción de Trinidad Sánchez Pacheco). Reseña: (1999). $A B C$ (ABC Cultural 382), 27-3, 27.

AMMANTI, Niccolò (1997). La última noche vieja de la humanidad. Barcelona: Mondadori (Traducción de Juan Vivanco). Reseña: GIRALTTORRENTE, Marcos (1997). «Las realidades feroces de Ammanti». El País (Babelia 282), 22-3, 12.

BofFA, Alessandro (1999). Eres una bestia, Viskovitz. Barcelona: Lumen (Traducción de Aldi Pérez). Reseña: Monmany, Mercedes (1999). «Relatos de bestias parlantes». El País (Babelia 391), 15-5, 11.

Camilleri, Andrea (1999). Un mes con Montalbano. Barcelona: Emecé (Traducción de Elena de Grau). Reseña: MoRA, Rosa (1999). «La irresistible ascensión de Camilleri». El País (Babelia 382), 6-3, 12.

Consolo. Vincenzo (1997). El olivo y el acebuche. Barcelona: Muchnik (Traducción de J. C. Gentile). Reseña: Cruz VARELA, María Elena (1998). «El olivo y el acebuche». $A B C$ (ABC Cultural 330), 27-2, 14.

JAEGGY, Fleur (1998). El temor del cielo. Barcelona: Tusquets (Traducción de Flavia Company). Reseñas: MonManY, Mercedes (1998). «Una dulce perversión». El País (Babelia 327), 7-2, 13. HeRnanz, Beatriz (1998). «El temor del cielo». $A B C$ (ABC Cultural 329), 20-2, 14.

LeVI, Primo (1998). Lilit y otros relatos. Barcelona: Muchnik Editores. Reseña: Solano, F. (1998). «Lilit y otros relatos». $A B C$ (ABC Cultural 355), 17-9, 27.

MANGANELl, Giorgio (1997). La noche. Barcelona: Muchnik Editores (Traducción de J. C. Gentile; Epílogo de Salvatore Silvano Nigro). Reseña: PuJol, Carlos (1997). «La noche». ABC (ABC Cultural 311), 17-10, 12.

Moravia, Alberto (1996). Paraíso. Barcelona: Altera (Traducción de Juan Moreno). Reseña: J. E[rnesto] A[YALA]-D[IP] (1996). «Uno de los hallazgos narrativos de Moravia». El País (Babelia 242), 15-6, 11.

PASA, Mario (1997). El escritorio de las maravillas. Barcelona: Península. Reseña: M[arcos] G[IRALT]-T[ORRENTE] (1997). «Siete cuentos como una novela». El País (Babelia 308), 17-9, 8.

TABUCCHI, Antonio (1996). Sueño de sueños. Los tres últimos días de Pessoa. Barcelona: Anagrama (Traducción de C. Gumpert y X. González). 
Reseña: MARCo, Joaquín (1996). «Sueño de sueños. Los tres últimos días de Pessoa». ABC (ABC Cultural 241), 14-6, 12.

b) Antologías

BuZZATI, Dino (1996). Los siete mensajeros y otros relatos. Madrid: Alianza

(Selección y traducción de Javier Setó). Reseñas: GuelBENZu, José María (1996). «Buzzati, un maestro en crear ambientes». El País (Babelia 227), 24-2, 15. CUENCA, Luis Alberto de (1996). «Los siete mensajeros y otros relatos». $A B C$ ( $A B C$ Cultural 246), 19-7, 13.

VV.AA. (1998). Juventud caníbal. Madrid: Grijalbo/Mondadori (Edición de

Danielle Brolli, traducción de Juan Vivanco). Reseña: NAVARRo, Justo (1998). «Jóvenes caníbales: otra mutación». El País (Babelia 338), 2-5, 9.

\section{Miscelánea de varios idiomas}

VV.AA (s.d). No todos los vampiros.... Barcelona: Acervo (Traducción de A. Sánchez Vera, A. Herrera, J. M. Aroca y A. Vidal). Reseña: CuENCA, Luis Alberto de (1996). «No todos los vampiros...». ABC (ABC Cultural 264), 22-11, 8.

VV.AA. (1995). Historias de gatos. Barcelona: Montesinos (Varios traductores). Reseña: M[arcos] G[IRALT]-T[ORRENTE] (1996). «Actitudes felinas en la literatura». El País (Babelia 227), 24-2, 11.

VV.AA. (1996). Quince líneas. Relatos hiperbreves. Barcelona: Tusquets (Premio Internacional de Relato Hiperbreve). Reseña: M. A. C. (1996). «Inquietantes, sugestivos, son suspiros literarios». El País (Babelia 280), 8-3, 9.

VV.AA. (1997). Cuentos populares gitanos. Madrid: Siruela (Edición de Diane Tong; traducción de Alfonso Gómez Cedillo). Reseña: VILAMATAS, Enrique (1997). «Del fabuloso ingenio gitano». El País (Babelia 286), 26-4, 8.

VV.AA (1997). Antología del cuento triste. Madrid: Alfaguara (Edición de Augusto Monterroso y Bárbara Jacobs). Reseñas: CoNTE, R[afael] (1997). «Antología del cuento triste». $A B C$ ( $A B C$ Cultural 313), 31-10, 24. Ayala-DIP, J. Ernesto (1997). «Los maestros de la tristeza». El País (Babelia 316), 22-11, 10.

VV.AA. (1998). Cuentos del Marruecos español. Madrid: Clan Editorial (Recopilación e introducción de El Hassane Arabi; prólogo de Abdellatif Limami; ilustraciones de Mariano Bertuchi). Reseña: BAYón, Miguel (1999). «Para que el estrecho se estreche». El País (Babelia 373), 2-1, 6. 
VV.AA (1998). Las mejores historias sobre gatos. Madrid: Siruela (Traducción de María Corniero, María Isabel Reverte, María Teresa Gallego y Elisa Lucena). Reseñas: CASTEJón, Encarna (1998). «Las encarnaciones del gato». $A B C$ (ABC Cultural 369), 24-12, 14. HARGUINDEY, Ángels S. (1999). «Amores sin fronteras». El País (Babelia 375), 16-1, 8.

VV.AA. (1998). La memoria de los cuentos. Un viaje por los cuentos populares del mundo. Madrid: Espasa (Edición de Miguel Díez Rodríguez y Paz Díez Taboada. Prólogo de Luis Mateo Díez). Reseña: Pozuelo Yvancos, José María (1999). «En el principio fue el cuento». $A B C$ ( $A B C$ Cultural 373), 21-1, 19.

VV.AA. (1998). Cuentos sorprendentes. Madrid: Popular. Reseña: J[uan] M[ARín] (1999). «Relatos de lo inesperado». El País (Babelia 378), 6-2, 6. VV.AA (1999). Los 120 mejores cuentos de las tradiciones espirituales de Oriente. Madrid: Edaf (Edición de Ramiro Lacalle y Sebastián Vázquez). Reseña: DíAz-GuARDIOLA, Javier (1999). «Los 120 mejores cuentos de las tradiciones espirituales de Oriente». $A B C$ ( $A B C$ Cultural 404), 23-10, 31.

\section{Las lenguas menos traducidas}

\section{1. Árabe}

AL-SHAYKIN, Hanan (1996). Mujeres de arena y mirra. Barcelona: Ediciones del Bronce (Traducción de P. Todó y L. M. Todó). Reseña: CRUZ VARELA, María Elena (1996). «Mujeres de arena y mirra». $A B C$ (ABC Cultural 252), 30-8, 11.

MAHFUZ, Naguib (1996). Las noches de las mil y una noches. Barcelona: Plaza \& Janés (Traducción de María Luisa Prieto). Reseña: BAYón, Miguel (1996). «El Faraón de Gamaliya». El País (Babelia 242), 15-6, 12. VV.AA. (1996). Bajo la Jaima, cuentos populares del Sáhara. Madrid: Miraguano (Edición de Fernando Pinto Cebrián y Antonio Jiménez Trigueros). Reseña: GIRALT ToRRENTE, Marcos (1996). «Cuentos del Tíbet y del Sáhara». El País (Babelia 253), 31-8, 6.

VV.AA (1999). Escritoras árabes. Barcelona: Icaria (Edición de Encarna Cabello. Varios traductores). Reseña: GARCíA, Concha (1999). «No hay sitio en el paraíso». $A B C$ ( $A B C$ Cultural 399), 18-9, 22.

\subsection{Checo}

DuRYCH, Jaroslav (1998). Réquiem. Madrid: Ediciones de Oriente y del Mediterráneo (Prólogo y traducción de Clara Janés). Reseña: MonMANY, 
Mercedes (1999). «Muerte y terror en la guerra». El País (Babelia 382), 6-3, 10.

HraBaL, Bohumil (1997). Los palabristas. Barcelona: Destino (Traducción de Eva Kruntarádová y Nuria Mirabet). Reseñas: J. M. G. (1997). «Los palabristas». El País (Babelia 291), 31-5, 6. LECH, Iury (1997). «Magisterio de la fabulación». El País (Babelia 296), 5-7, 9.

\subsection{Chino}

ANóNIMO (1998). Bella de Candor y otros relatos chinos. Barcelona: Tusquets (Traducido del francés por Mercedes y María Corral). Reseña: C. M. S. (1998). «Sugestivos cuentos eróticos». El País (Babelia 348), 11-6, 10.

\subsection{De Corea del Sur}

Yun, Ch'oe (1996). Él vigila a su padre. Barcelona: Circe (Traducción de Ana María Moix y Concha Serra Ramoneda). Reseña: GIRALT-TORRENTE, Marcos (1996). «Tres retratos de dolor». El País (Babelia 7-12, 7.

\subsection{De India}

TAGORE, Rabindranath (1996). Cuentos. Madrid: PPC (Traducción de A. García Galiano). Reseña: M[arcos] G[IRALT]-T[ORRENTE] (1997). «Las bellas fábulas de Rabindranath Tagore». El País (Babelia 280), 1-3, 14. VV.AA. (1997). Cuentos hindúes. Barcelona: Paidós (Traducción de Paz Ortega Montes; edición de Johannes Hertel). Reseña: M[arcos] G[IRALT]T[ORRENTE] (1997). «Textos y relatos del fascinante mundo hindú». $E l$ País (Babelia 304), 30-8, 11.

\subsection{De los países nórdicos}

DINESEN, I. (1998). La familia Cats / Caballos fantasmas. Barcelona: Plaza y Janés (Colección «Relatos» dirigida por Ana María Moix). Reseña: Pujol, Carlos (1998). «Trayectos cortos». $A B C$ (ABC Cultural 356), $24-$ $9,14$.

VV.AA (1997). Hijas del frío. Madrid: Ediciones de la Torre (Prólogo de Lourdes Ortiz). Reseña: PuJol, Carlos (1997). «Hijas del frío». $A B C$ (ABC Cultural 301), 8-8, 12. 
VV.AA (1999). El vikingo afeitado (Relatos de escritores nórdicos). Madrid: Ediciones de la Torre (Antología preparada por Eva Liébana, Úrsula Ojanen, Kristinn R. Ólafsson, Kirsti Baggethum y Martin Lexel; prólogo de Jesús Ferrero). Reseña: I. F. (1999). «Cotidianidad nórdica». El País (Babelia 411), 2-10, 8.

\subsection{De Nepal}

VV.AA. (1997). Cuentos y leyendas del Nepal. Palma de Mallorca: José J. de Olañeta (Introducción, recopilación y traducción de Víctor Giménez Morote; edición de José J. de Olañeta). Reseña: GiRALT-ToRRENTE, Marcos (1998). «El caudal popular de Nepal».El País (Babelia 326), 31-1, 10.

\subsection{De Países Balcánicos}

VV.AA. (1995). Cuentos fantásticos de los Balcanes. Madrid: Compañía Literaria (Edición de Vuck Stefanovic Karadzic y G. K. Stefanovic; traducción de Pilar Dolado). Reseña: Giralt TorRente, Marcos (1996). «Discípulos de Grimm». El País (Babelia 225), 10-2, 16.

\subsection{De Tíbet}

VV.AA. (1996). Cuentos eróticos y mágicos de mujeres nómadas tibetanas. Barcelona: Paidós (Edición de Margret Causemann; traducción de Olga Domínguez Scheidereiter). Reseña: GiRALT-ToRRENTE, Marcos (1996). «Cuentos del Tíbet y del Sáhara». El País (Babelia 253), 31-8, 6.

\subsection{Griego moderno}

IOANU, Yorgos (1998). El sarcófago. Valladolid: Universidad de Valladolid (Traducción de Amor López, Elisa Ibáñez y Román Bermejo). Reseña: C[arlos] G[ARCía] G[UAL] (1998). «Evocación de Salónica en los tiempos de penuria». El País (Babelia 365), 7-11, 11.

TAKTSIs, Costas (s.d). Las vueltas. Madrid: Ediciones del Oriente y del Mediterráneo (Traducción de N. Gálvez). Reseñas: HeRnANZ, Beatriz (1996). «Las vueltas». $A B C$ ( $A B C$ Cultural 269), 27-10, 8. GuelbenZu, José María (1996). «El matriarcado devorador de Taktsis». El País (Babelia 268), 14-12, 12. 


\subsection{Hebreo}

KATZIR, Yehudit (1996). Cerrando el mar. Barcelona: Lumen (Traducción de Ana María Bejarano). Reseñas: M[aría] J[osé] O[BIOL] (1996). «Los cuentos de Yehudit Katzir». El País (Babelia 265), 23-11, 15. Hernanz, Beatriz (1997). «Cerrando el mar». ABC (ABC Cultural 278), 28-2, 12.

\subsection{Japonés}

Mishima, Yukio (1996). La perla. Madrid: Siruela (Traducción de M. Ruiz Guiñazu y A. Cabezas). Reseña: R. B. (1996). «Diez relatos del japonés Yukio Mishima». El País (Babelia 226), 17-2, 8.

- (1996). La perla y otros cuentos. Madrid: Siruela (No se indica el traductor) Reseña: D. C. (1996). «Clásicos y grandes éxitos, en bolsillo». El País (Babelia 240), 1-6, 12.

OÉ, Kenzaburo (1995). Dinos como sobrevivir a nuestra locura. Barcelona: Anagrama (Traducción de S. Suzuki y E. Vilageliu). Reseña: SÁNCHEZOstIZ, Miguel (1996). «Dinos como sobrevivir a nuestra locura». ABC (ABC Cultural 221), 26-1-96: 12.

\subsection{Kurdo}

SAMANCI, Suzan (1999). Hélin olía a resina. Tafalla: Txalaparta (Traducción de Mikel Arizaleta). Reseña: M[arcos] G[IRALT]-T[ORRENTE] (1999). «En la tradición oral de los cuentos kurdos». El País (Babelia 406), 28-8, 6.

\subsection{Polaco}

MrozeK, Slawomir (1998). Dos cartas. Barcelona: Quaderns Crema (Traducción de J. M. De Sagarra). Reseña: MonMANY, Mercedes (1998). «Slawomir Mrozek, poeta de lo cómico». El País (Babelia 349), 18-7, 10.

- (1998). El árbol. Barcelona: Quaderns Crema (Traducción de B. Zaboklikca y F. Miratvilles). Reseña: MonManY, Mercedes (1998). «Slawomir Mrozek, poeta de lo cómico». El País (Babelia 349), 18-7, 10.

PoтоскI, Jan (1996). Manuscrito encontrado en Zaragoza. Barcelona: Minotauro (Prólogo de Roger Callois y traducción de José Bianco). Reseña: J. E[rnesto] A[YALA]-D[IP] (1996) «Las historias mágicas de Jan Potocki». El País (Babelia 258), 5-10, 11. 


\subsection{Portugués}

TorgA, Miguel (1998). Bichos. Madrid: Alfaguara (Traducción de E. Álvarez). Reseña: García Martín, José Luis (1998). «Bichos». ABC (ABC Cultural 332), 13-3, 15.

\subsection{Ruso}

Berberova, Nina (1996). Las damas de San Petersburgo. Barcelona: Circe (Traducción de Selma Ancira). Reseñas: AYALA-DIP, J. Ernesto (1996). «Huir de la revolución rusa». El País (Babelia 268), 14-12, 12. CRUZ VARELA, María Elena. "Las damas de San Petersburgo». ABC (ABC Cultural 274), 31-1, 13.

CHÉJov, A. (1998). Enemigos / Ionich. Barcelona: Plaza y Janés (Colección «Relatos» dirigida por Ana María Moix). Reseña: Pujol, Carlos (1998). «Trayectos cortos». ABC (ABC Cultural 356), 24-9, 14.

Platónov, Andréi (1999). La patria de la electricidad y otros relatos. Barcelona: Galaxia Gutenberg / Círculo de Lectores (Traducción de José Manuel Prieto. Epílogo de Jorge Semprún). Reseña: ANDREsco, Víctor (1999). «Pan, luz y lectura». $A B C$ (ABC Cultural 408), 20-1199: 13.

PusHKIN, Aleksander (1999). Relatos del difunto Iván Petrovich Belkin. Barcelona: Áltera (Traducción, introducción y notas de Ricardo San Vicente). Reseña: M[arcos] G[IRALT]-T[ORRENTE] (1999). «Cuentos de Pushkin». El País (Babelia 401), 24-7, 9.

VV.AA. (1997). En la oscuridad. Madrid: Trotta (Edición y traducción de Miguel Ángel Chao Valls). Reseña: GIRALT-ToRRENTE, Marcos (1997). «Bajo la sombra de Chéjov». El País (Babelia 304), 30-8, 11.

VV.AA. (1998). Escritoras rusas. Barcelona: Icaria (Traducción de Margarita Estapé). Reseña: FreIXAS, Laura (1998). «Depresión pos-soviética». El País (Babelia 350), 25-7, 8.

\subsection{Turco}

Sevgo OzDaMar, Emine (1996). La lengua de mi madre. Madrid: Alfaguara (Traducción de Miguel Sáenz). Reseña: OBIOL, María José (1996). «La memoria y su idioma original». El País (Babelia 258), 5-10, 10.

SEYFETTIN, Omar (1996). Cuentos turcos de ayer. Madrid: Hiperión. Reseña: M[arcos] G[IRALT]-T[ORRENTE] (1996) «Entre oriente y occidente». $E l$ País (Babelia 241), 8-6, 14. 


\section{Traducciones de idioma desconocido}

Poch, Reny (1996). El miradero de la luna. Irún: Iralka (Sin referencia al traductor). Reseña: L[uis] DE LA P[EÑA]. (1996). «Una mirada burlona sobre un mundo caótico». El País (Babelia 252), 24-8, 9.

VV.AA. (1997). Cuentos y leyendas Masai. Madrid: Miraguano (Edición de Alfredo Franceschi). Reseña: M[arcos] G[IRALT]-T[ORRENTE] (1997). «Mitología sobre los cazadores de leones». El País (Babelia 300), 2-8, 7.

\section{Versiones originales}

\subsection{Inglés}

GARNER, James Finn (1995). Politically correct bedtime stories. Nueva York: MacMillan. Reseña: Haro TECGLEN, Eduardo. «Los cuentos corregidos». El País (Babelia 223), 27-1, 14.

\subsection{Gallego}

BorRaZÁs, Xurxo (1998). Contos malvados. Vigo: Editorial Xerais. Reseña: BASANTA, Ángel (1998). «Contos malvados». ABC (ABC Cultural 351), 24-7, 24.

Murado, Miguel Anxo (1998). Mércores de cinza. Vigo: Galaxia. Reseña: BASANTA, Ángel (1998). «Mércores de cinza». ABC (ABC Cultural 342), 22-5, 23.

\section{CONCLUSIONES}

En las siguientes líneas exponemos algunas reflexiones sobre nuestro trabajo de recopilación de reseñas de cuentos en los suplementos culturales de dos diarios: El País y $A B C$. José Romera Castillo, director del Instituto de Semiótica Literaria, Teatral y Nuevas Tecnologías, nos propuso la realización de un trabajo de investigación que consistía básicamente en el rastreo y ordenación de todas las reseñas que sobre cuentos hubieran aparecido en Babelia y $A B C$ Cultural entre el primero de enero de 1996 y el 31 de diciembre de 1999. Nuestro estudio debía ser complementario y sucesivo al realizado por Felipe Díaz Pardo, que según se puede ver en el trabajo anterior abarca desde 1991 a 1995. Las conclusiones que nosotros ofrecemos, en muchos de los casos, son semejantes a las expuestas por el citado investigador. 
El conjunto de los suplementos de $A B C$ Cultural consultados contiene un total de 219 reseñas de otros tantos libros diferentes, siendo - como se refleja en el cuadro siguiente- los procedentes de autores españoles los más comentados:

\begin{tabular}{lccc}
\hline Lengua de origen & Obras & Antologías & Total \\
\hline Alemán & 8 & 0 & 8 \\
\hline Árabe & 2 & 0 & 2 \\
\hline Catalán & 3 & 0 & 3 \\
\hline Español (España) & 90 & 12 & 102 \\
\hline Español (Hispanoamérica) & 24 & 3 & 27 \\
\hline Francés & 8 & 0 & 8 \\
\hline Gallego & 4 & 0 & 4 \\
\hline Griego moderno & 1 & 0 & 1 \\
\hline Hebreo & 1 & 0 & 1 \\
\hline Inglés & 39 & 3 & 42 \\
\hline Italiano & 6 & 1 & 7 \\
\hline Japonés & 1 & 0 & 1 \\
\hline Miscelánea & 5 & 0 & 5 \\
\hline Paises nórdicos & 1 & 1 & 2 \\
\hline Portugués & 1 & 0 & 1 \\
\hline Ruso & 3 & 0 & 3 \\
\hline Versiones originales & 2 & 0 & 2 \\
\hline \multicolumn{1}{c}{ Total } & 199 & 20 & 219 \\
\hline
\end{tabular}

En Babelia el número total de reseñas es de 325 distribuidas como sigue:

\begin{tabular}{lccc}
\hline Lengua de origen & Obras & Antologías & Total \\
\hline Alemán & 9 & 0 & 9 \\
\hline Árabe & 2 & 0 & 2 \\
\hline Catalán & 5 & 0 & 5 \\
\hline Checo & 3 & 0 & 3 \\
\hline Chino & 1 & 0 & 1 \\
\hline De Corea & 1 & 0 & 1 \\
\hline De India & 2 & 0 & 2 \\
\hline De Nepal & 1 & 0 & 1 \\
\hline De Tibet & 1 & 0 & 1 \\
\hline Español (España) & 113 & 18 & 131 \\
\hline
\end{tabular}


FRANCISCO LINARES Y DOLORES ROMERO LÓPEZ

\begin{tabular}{lccc}
\hline Lengua de origen & Obras & Antologías & Total \\
\hline Español (Hispanoamérica) & 44 & 9 & 53 \\
\hline Francés & 7 & 1 & 8 \\
\hline Gallego & 5 & 0 & 5 \\
\hline Griego moderno & 3 & 1 & 4 \\
\hline Hebreo & 1 & 0 & 1 \\
\hline Inglés & 61 & 5 & 66 \\
\hline Italiano & 6 & 2 & 8 \\
\hline Japonés & 2 & 0 & 2 \\
\hline Kurdo & 1 & 0 & 1 \\
\hline Miscelánea & 0 & 8 & 8 \\
\hline Paises Balcánicos & 1 & 0 & 1 \\
\hline Paises Nórdicos & 1 & 0 & 1 \\
\hline Polaco & 3 & 0 & 3 \\
\hline Portugués & 1 & 0 & 1 \\
\hline Ruso & 4 & 0 & 4 \\
\hline Turco & 2 & 0 & 2 \\
\hline Versiones originales & 1 & 0 & 1 \\
\hline Total & 282 & 43 & 325 \\
\hline
\end{tabular}

El total de reseñas publicadas es de 544 y quedan representadas así:

\section{LIBROS DE CUENTOS SEGÚN LENGUAS DE PROCEDENCIA (1996-1999)}

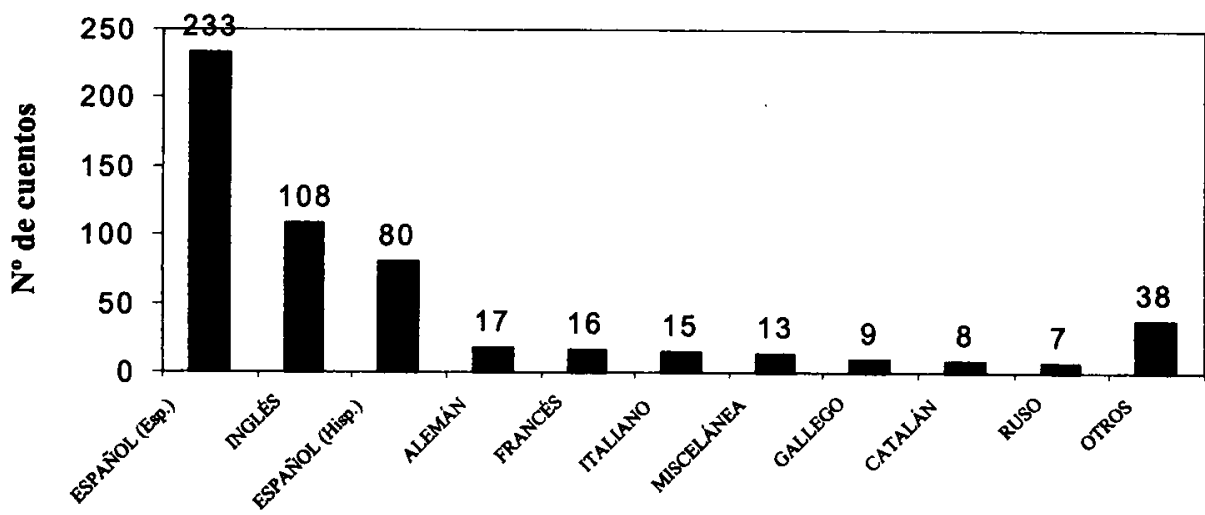

Lenguas de procedencia 
Si comparamos este cuadro con el facilitado por Felipe Díaz Pardo en el trabajo anterior para los años 1991 a 1995 nos damos cuenta de dos hechos:

1. El número de reseñas sobre cuentos ha crecido en los últimos años.

2. Ha ascendido el número de las traducciones, sobre todo de las consideradas como escasas o raras en nuestra lengua.

En cuanto a la metodología utilizada, hemos clasificado el apéndice en función del idioma del que se ha traducido y dentro de cada uno de estos grupos se ha hecho la distinción entre obras originales y antologías.

Las conclusiones a las que hemos llegado son las siguientes:

1. Los límites terminológicos del género cuento son difusos. Aparecen diversas formas para aludir a él. ¿Qué diferencia existe entre «cuento» y «novela corta» 1 ? Bajo la terminología de «cuento» se alude en alguna reseña a textos que tienen hasta ciento once páginas ${ }^{2}$. La confusión es similar entre «cuento» y el término «historia» ${ }^{3}$, que desde el punto de vista narratológico actúa como sinónimo. Luis de la Peña anota estas imprecisiones y reconoce a propósito del libro La señora Rodríguez y otros mundos, de Martha Cerda que: «Uno no sabe, cuando comienza a leer este libro, si se encuentra ante una colección de cuentos o una novela» 4 . Por otra parte, tampoco parece homogénea la distinción entre «cuento», «relato» 5 , «relato corto» 6 y «novela en relatos» 7 . Esta variada terminología no debe entenderse como una dificultad para su estudio, sino como una nota más de la riqueza estética y formal que abarca el género.

2. La atención de los críticos se centra, fundamentalmente, en cuentos contemporáneos, entendiendo éstos como los de autores que desarrollan su labor

1 Término al que alude Miguel García-Posada en una reseña publicada en el número 391 de Babelia sobre el texto de Manuel de Lope, Música para tigres.

2 VON GOETHE, Johann Wolfgang (1999). La serpiente verde. Barcelona: Herder (Traducción de Ángela Ackermann). Reseña: I. L. (1999). «Un cuento preciosista de Goethe». El País (Babelia 390), 8-5, 9 .

3 DE VILLENA, Luis Antonio (1999). El mal mundo. Barcelona: Tusquets (XXI Premio «La Sonrisa Vertical»). Reseña: GoÑI, Javier (1999). «Pasión y melancolía». El País (Babelia 389), $1-5,7$.

4 CERDA, Martha (1999). La señora Rodríguez y otros mundos. Barcelona: Ediciones B. Reseña: DE LA PEÑA, Luis (1999). «El mundo dentro de un bolso». El País (Babelia 415), 30-10, 10.

5 DE LA Rosa, Julio Manuel (1997). La columna y otros relatos. Sevilla: Alfar. Reseña: GARCÍA-PosadA, Miguel (1997). «Mitos y realidades». El País (Babelia 303), 23-8, 9. DE PRADA SAMPER, José Manuel (1998). Las mil caras del diablo. Barcelona: Juventud (Ilustraciones de Luis Filella). Reseña: R. B. (1998). «Relatos sobre el diablo de 30 culturas diferentes». El País (Babelia 360), 3-10, 10.

6 Montero, Rosa (1998). Amantes y enemigos (Cuentos de parejas). Madrid: Alfaguara. Reseñas: FUERTES, Sol (1998). «Rosa Montero o el amor es una mentira». El País (Babelia 336), 18-4, 12. CASTRO, Pilar (1998). ABC (ABC Cultural 338), 24-4, 14.

7 QUIÑONES, Fernando (1997). El coro de dos voces. Madrid: Anaya \& Mario Muchnik. Reseña: Pereda, Rosa (1997). «No es bueno ser simpático». El País (Babelia 287), 3-5, 12. 
literaria en fechas recientes. El interés de la crítica por ediciones de autores españoles de periodos anteriores a la Guerra Civil es escasa: apenas unas reseñas para comentar La mujer alta. La Comendadora, de Pedro Antonio de Alarcón; Cuentos de amor y muerte, de Pío Baroja; Contando sus pasos, de Corpus Barga; Narraciones completas; de Pedro Salinas y Cuentos fantásticos, de Benito Pérez Galdós ${ }^{8}$. Esta falta de atención por parte de los editores, y consiguientemente de la crítica, a la cuentística clásica española da cuenta de la revitalización del género que cubre ampliamente las expectativas editoriales, alimentándose casi únicamente de autores pertenecientes a la segunda mitad del siglo XX.

Conclusiones de signo similar arrojan las antologías de cuentos de autores españoles. Cien años de cuentos (1898-1998. Antología del cuento español en castellano) ${ }^{9}$ ofrece un panorama sobre la cuentística de la totalidad del siglo XX, mientras que el resto de ellas se limitan a una visión parcial o más delimitada temporalmente. Entre estas últimas quizá destaque, por su repercusión entre la crítica y público, Páginas amarillas ${ }^{10}$, donde se dan cita los narradores de la última generación.

3. La práctica totalidad de los libros reseñados están escritos por narradores, bien consagrados ya por la crítica, o noveles, aunque algunos cultivadores de otros géneros hacen incursiones en el cuento corto. Algunos poetas como Felipe Benítez Reyes (Maneras de perder) o Luis Antonio de Villena (El mal mundo; La fascinante moda de la vida) se sumergen en el género corto con distinta fortuna; otros como el político y diplomático Fernando Morán se valen de su experiencia profesional para introducirse, no por primera vez, en el mundo de la fabulación (El día en que...).

4. El cuento escrito por autores hispanoamericanos tiene, a pesar de su escasa representación, un peso específico importante. Autores como Mario

8 AlARCón, Pedro Antonio de (1998). La mujer alta. La comendadora. Barcelona: Plaza y Janés. Reseña: C[arlos] P[UJoL] (1998), «La mujer alta/La comendadora». ABC (ABC Cultural 354), 10-9, 14.

BaRga, Corpus [Seud. de Andrés García de la Barga y Gómez] (1997). Contando sus pasos. Valencia: Pre-Textos (Edición de Isabel del Álamo). Reseña: Pujol, Carlos (1998). «Contando sus pasos». $A B C$ ( $A B C$ Cultural 328), 13-2, 15.

Baroja, Pío (1997). Cuentos de amor y muerte. Madrid: Ediciones Clan (Introducción de Jesús Gálvez Yagüe e ilustraciones de Marina Arespacochaga). Reseña: CoNTE, R[afael]. «Cuentos de amor y de muerte». $A B C$ ( $A B C$ Cultural 306), 12-9, 20.

Pérez Galdós, Benito (1996). Cuentos fantásticos. Madrid: Cátedra (Edición de Alan E. Smith). Reseña: SENABRE, Ricardo (1996). ABC (ABC Cultural 237), 17-5, 19

Salinas, Pedro (1998). Narraciones completas. Barcelona: Península. Reseña: Conte, Rafael (1998). «Narraciones completas». $A B C$ (ABC Cultural 352), 31-7, 11.

9 VV.AA (1998). Cien años de cuentos (1898-1998). Antología del cuento español en castellano. Madrid: Alfaguara (Selección y prólogo de José María Merino). Reseña: CASTEJón, Encama (1998). «El oído y la memoria» $A B C$ ( $A B C$ Cultural 363), 12-11, 11.

10 VV.AA (1997). Páginas amarillas. Madrid: Lengua de Trapo (Introducción de Sabas Martín). Reseña: ConTe, Rafael (1998). «Páginas amarillas». $A B C$ (ABC Cultural 322), 2-1, 11. 
Benedetti ${ }^{11}$, Francisco Coloane ${ }^{12}$, José Lezama Lima ${ }^{13}$, Augusto Monterrosso ${ }^{14}$, o el felizmente recuperado Julio Ramón Ribeyro ${ }^{15}$ son muestra de ello, y cuentan con el favor unánime de la crítica. Tres antologías completan el panorama de esta narrativa escrita en tierras sudamericanas.

Estudio especial merecen las traducciones. La traducción se ha considerado siempre como una actividad secundaria al talento que implica la creación. Desde 1970 un grupo de teóricos comienzan a defender los estudios de traducción. Itamar Even-Zohar en un artículo titulado «The Position of Translated Literature within the Literary Polysystem» - recientemente traducido al castellano en el volumen Teoría de los polisistemas (1999)- propone un estudio sistémico de las traducciones. ¿Cuál sería, pues, la función de los cuentos traducidos dentro del sistema literario dominante de la lengua castellana? ¿Por qué se traducen más cuentos de unas lenguas que de otras?¿Qué autores de cuentos se traducen? ¿Qué obras se traducen? ¿Qué estatus ocupan los cuentos traducidos dentro de la literatura en lengua castellana? ¿Qué relación mantienen los textos traducidos respecto a los canóni$\cos$ ? El número total de textos en castellano es de 544 . El número total de traducciones es de 231, es decir, casi la mitad de las reseñas de cuentos están basadas sobre traducciones, lo cual permite establecer algunas conclusiones:

1. Con respecto a las traducciones de otras lenguas nacionales de España, el catalán y el gallego cuentan con algún libro en nómina. Sobre todos los reseñados en ambas lenguas, destaca por su calidad y actualidad la figura de Manuel Rivas, escritor gallego que se alza con el favor de crítica y público con dos libros esenciales: ¿Qué me quieres amor? y Ella, maldita alma ${ }^{16}$. Es obvio que la actual política de normalización linguiística ha favorecido la pro-

11 BenedeTti, Mario (1999). Buzón de tiempo. Madrid: Alfaguara. Reseña: Álvarez GARrigA, Carles (1999). «A ratos, Benedetti». $A B C$ (ABC Cultural 409), 27-11, 14.

12 Coloane, Francisco (1999). Cuentos completos. Madrid: Alfaguara (Prólogo de José María Guelbenzu). Reseña: RodríGuEz-FISCHER, Ana (1999). «Épica en las Antípodas». $A B C$ (ABC Cultural 396), 10-7, 19.

13 Lezama Lima, José (1999). Relatos. Madrid: Alianza. Reseña: CASTRO, Antón (1999). «El poeta y la alquimia verbal». $A B C$ ( $A B C$ Cultural 409), 27-11, 15.

14 Monterrosso, Augusto (1999). Antología personal. Madrid: Visor (con CD-ROM). Reseña: OrTEGA, Antonio (1999). «Monterroso, la vida». $A B C$ ( $A B C$ Cultural 395), 3-7, 11.

15 RibeYro, Julio Ramón (1998). Silvio en el Rosedal. Barcelona: Plaza y Janés (Colección «Relatos» dirigida por Ana María Moix). Reseña: Pujol, Carlos (1998). «Trayectos cortos». $A B C$ (ABC Cultural 356), 24-9, 14.

- (1998). Cuentos (Antología). Madrid: Espasa (Edición de Ángel Esteban). Reseña: MARTÍNEZ DE PISÓN, Ignacio (1998). «Un nuevo clásico». ABC (ABC Cultural 370), 31-12, 13.

16 RIvAs, Manuel (1996). ¿Qué me quieres amor? Madrid: Alfaguara (Traducción de Dolores Vilavedra). Reseña: SENABRE, Ricardo (1996). "¿Qué me quieres amor?». ABC (ABC Cultural 244), 5-7, 11.

- (1999). Ella, maldita alma. Madrid: Alfaguara (Traducción y notas de Dolores Vilavedra). Reseña: CASTRO, Antón (1999). «El paisaje, el enigma y la lluvia». $A B C$ ( $A B C$ Cultural 406), 6$11,17$. 
ducción literaria de las literaturas vasca, gallega y catalana. Las traducciones al castellano parecen aún escasas. De todas formas no podríamos arriesgarnos a arrojar una valoración de las mismas porque carecemos de otros datos que darían fiabilidad a nuestras conclusiones, como por ejemplo las traducciones de otros géneros o las traducciones inversas. Permítasenos simplemente anotar la llamativa falta de reseñas de cuentos traducidos desde el vasco al castellano.

2. La primera lengua más traducida es el inglés: ciento ocho títulos merecen la atención de la crítica. La variedad de los autores representados es grande, siendo los más atendidos, al igual que ocurrió en el caso de los cuentos escritos en español, los autores de la segunda mitad del siglo $\mathrm{XX}$, aunque con algunas excepciones. Tal número de traducciones pone de manifiesto que el género cuento siempre ha gozado del favor de escritores y público dentro de la cultura anglosajona. Además ésta parece ser la influencia dominante en nuestra cultura. Llama la atención el número de obras dedicadas a temas relacionados con el terror y la fantasía: En la cripta, de H.P.; Lovecraft, Muerte entre bastidores y otros cuentos macabros, de Bram Stoker, y las antologías Malignos y macabros, Fantasmagoriana y El sudario de hierro y otros cuentos góticos.

3. Las reseñas sobre libros traducidos del alemán y el francés son menos numerosas - diecisiete y dieciséis respectivamente- y quince en italiano. La diferencia con respecto a las traducciones del inglés es ostensible. Esta disparidad se hace más llamativa cuando pasamos recuento a las traducciones del portugués: sólo dos. La proximidad de Portugal sigue siendo una mera cuestión geográfica, porque la atención que mostramos por la cultura y las producciones literarias del país vecino están a una distancia que, de momento, parece insalvable. Las reseñas sobre los cuentos traducidos del francés están basadas prácticamente en modelos «clásicos»: Albert Camus, Gustave Flaubert, Théophile Gautier, Pierre Loti, Mallarmé y George Sand. La tendencia es pues a traducir al castellano modelos franceses que ya han quedado petrificados dentro del sistema, y apenas se aportan nombres de última generación que podrían suponer una renovación de los clásicos. Lo mismo podríamos decir con el modelo de traducciones procedente del alemán (Hermanos Grimm, Hermann Hesse, Franz Kafka, Rainer Maria Rilke, Johann Wolfgang Von Goethe). Parece que los editores apuestan por nombres consagrados a la hora de ofrecernos traducciones de cuentos.

4. Las reseñas a otros libros de cuentos procedentes de traducciones consideradas como minoritarias muestran el relativo interés de la cultura hispánica hacia literaturas en conflicto como la balcánica, la checa o la minoría kurda; hacia las literaturas orientales (junto a la japonesa y la china ya clási- 
cas, emergen traducciones de cuentos de Nepal y Tibet). Siempre es éxito asegurado traducir del árabe Las mil y una noches, como lo es traducir los Cuentos de Tagore, en representación de la cultura hindú. De los países de la Europa Oriental aparecen algunas traducciones de cuentos polacos y rusos. Llaman la atención las reseñas que, dentro de las literaturas menos traducidas, se dedican a cuentos sobre mujeres. Algunos ejemplos son los volúmenes de Riana Scheepers, Mujeres zulúes; Hanan Al-Shaykin, Mujeres de arena y mirra y los Cuentos eróticos y mágicos de mujeres nómadas tibetanas. La traducción de esas lenguas actúa de forma minoritaria y periférica dentro del sistema, pero al mismo tiempo introduce un alto grado de renovación del mismo ya que aportan diversidad y diferencia a la literatura escrita en castellano.

Finalmente queremos indicar que tanto nuestro trabajo como el de Felipe Díaz Pardo -surgidos en el seno del equipo de investigación, dirigido por el profesor José Romera, y expuestos en el X Seminario Internacional del ISLTYNT (UNED)- podrán adquirir una mayor relevancia si se unen a los estudios publicados en el volumen de José Romera Castillo y Francisco Gutiérrez Carbajo (eds.), El cuento en la década de los noventa (Madrid: Visor Libros, 2001). 